\title{
Chemistry
}

\section{A European}

Journal

\section{Chemistry Europe}

European Chemical Societies Publishing

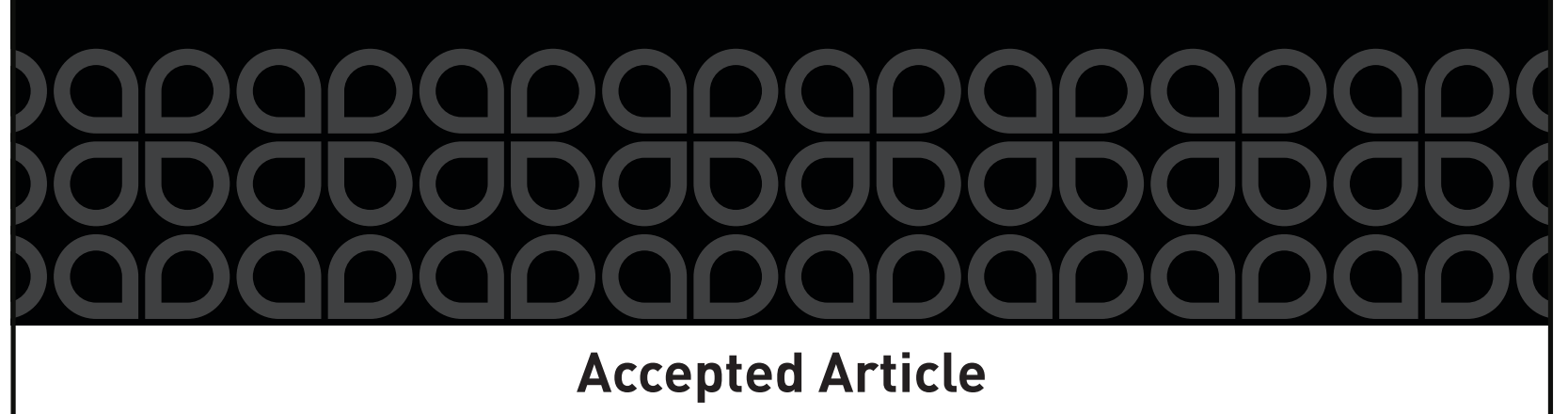

Title: New Visible Light-triggered Photocatalytic Trifluoromethylation Reactions of Carbon-carbon Multiple Bonds and (Hetero)aromatic Compounds

Authors: SEBASTIAN BARATA-VALLEJO and AI Postigo

This manuscript has been accepted after peer review and appears as an Accepted Article online prior to editing, proofing, and formal publication of the final Version of Record (VoR). This work is currently citable by using the Digital Object Identifier (DOI) given below. The VoR will be published online in Early View as soon as possible and may be different to this Accepted Article as a result of editing. Readers should obtain the VoR from the journal website shown below when it is published to ensure accuracy of information. The authors are responsible for the content of this Accepted Article.

To be cited as: Chem. Eur. J. 10.1002/chem.202000856

Link to VoR: https://doi.org/10.1002/chem.202000856 


\section{REVIEW}

\section{New Visible Light-triggered Photocatalytic Trifluoromethylation Reactions of Carbon-carbon Multiple Bonds and (Hetero)aromatic Compounds}

Sebastian Barata-Vallejo, ${ }^{[a, b]}$ Al Postigo ${ }^{\star[a]}$

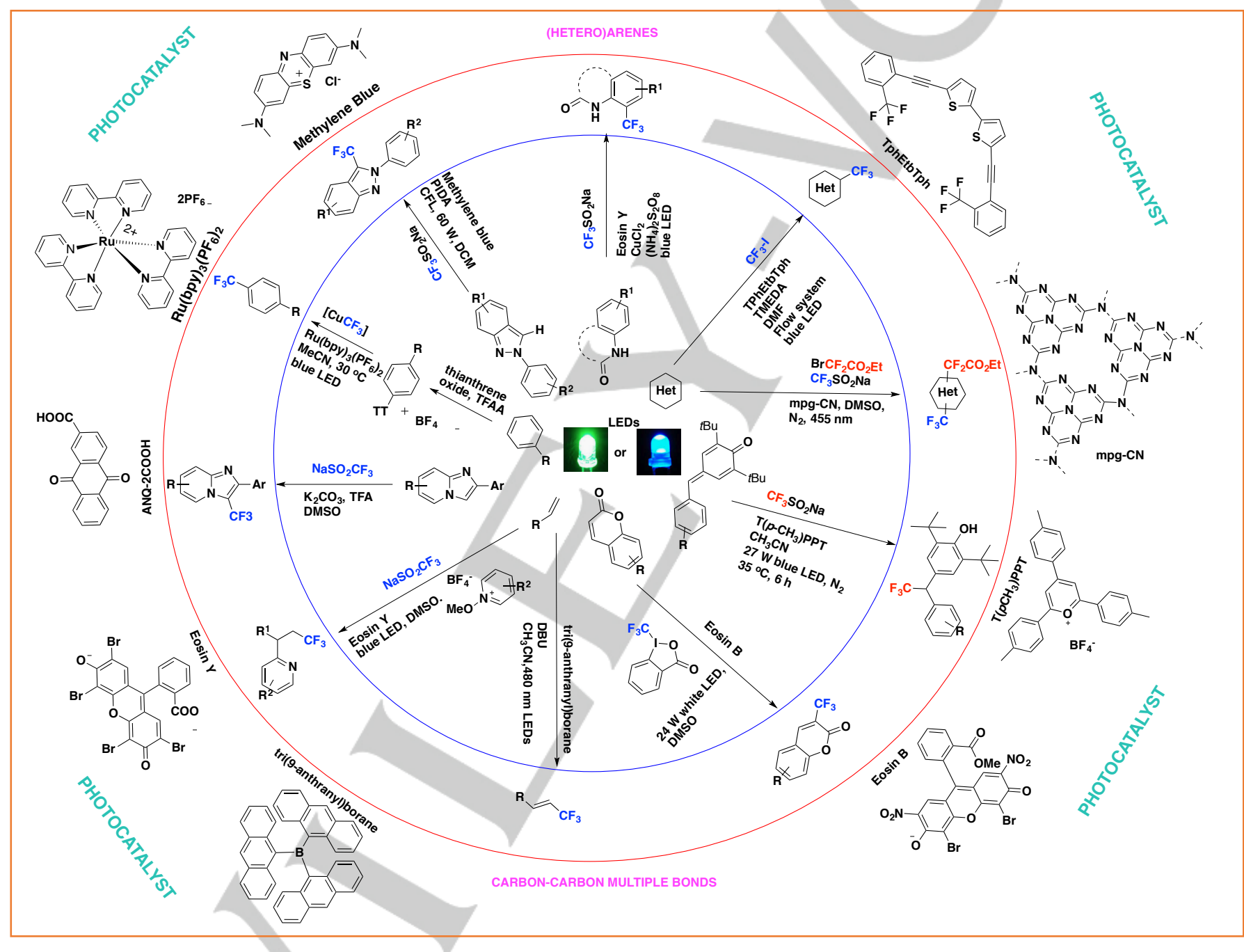


WILEY-VCH

[a] Dr. A. Postigo and Dr. S. Barata-Vallejo

Department of Organic Chemistry

Institution: Universidad de Buenos Aires, Facultad de Farmacia y Bioquímica,

Junin 954 CP 1113- Buenos Aires-Argentina

E-mail: apostigo@ffyb.uba.ar

[b] Dr. S. Barata-Vallejo. ISOF, Consiglio Nazionale delle Ricerche, Via P. Gobetti 101, 40129 Bologna, Italy

E-mail: sebastian.barata@isof.cnr.it

Abstract: Visible-light-photocatalyzed methods employed in synthetic transformations present attractive properties such as environmentally friendly, safety, availability and excellent functional group tolerance. In this venue, research on the visible-light photocatalytic incorporation of the trifluoromethyl $\mathrm{CF}_{3}$ moiety into organic substrates, in particular, has contributed to a clear evolution of the very field of photocatalysis. Outer-sphere electron transfers between photocatalysts and trifluoromethyl sources supply $\mathrm{CF}_{3}$ radicals efficiently in clean and controlled ways, capable of effecting numerous synthetic transformations and functionalization on organic substrates and compounds with pharmacological activity in straightforward manners. Although this particular area is constantly evolving and reviewed, the last five years have experienced an outburst of seminal and significant photocatalytic trifluoromethylation examples that are leading the way and opening new synthetic avenues. Recent review articles on Ru- and Ir- based photocatalytic trifluoromethylation reactions have borne witness of this evolution. Although this account will show the new Ru- and Ir-based photocatalytic trifluoromethylations, Sections 2 and 3 will also illustrate other photocatalytic systems, such as organic dyes, organic semiconductors and newly-developed all-organic photocatalysts. All the known and reviewed strategies for photocatalytic trifluoromethylation reactions of olefins and (hetero)aromatic compounds will not be discussed but will be summarized in two Figures (Figures 4 and 5), and new examples (2015-present) will be presented and discussed.

\section{Introduction}

\subsection{Pharmacological Relevance of $\mathrm{CF}_{3}$-containing Organic Compounds}

The incorporation of the $\mathrm{CF}_{3}$ group into organic substrates is conceived as a significant improvement of the chemistry and metabolism of drug candidates. There has been a notable increase in FDA-approved drugs [1] since 2015 that contain the $\mathrm{CF}_{3}$ moiety (Figure 1) showing remarkable pharmacological properties. The structures of the $\mathrm{CF}_{3}$-containing 2015-2019 FDAapproved drugs together with their modes of action are illustrated in Figure 1.[2-10]

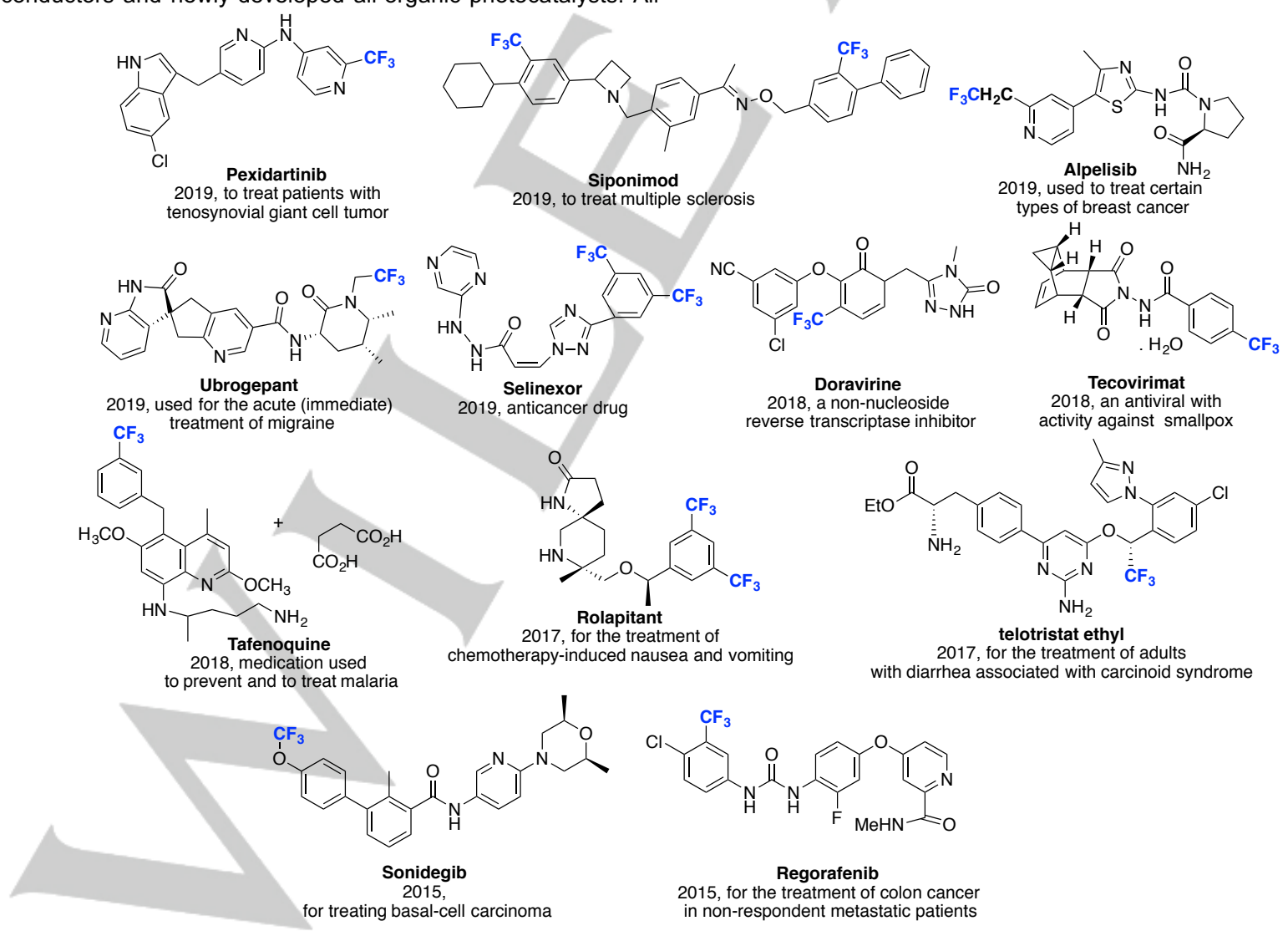

Figure 1. 2015-2019 approved FDA-drugs that contain the $\mathrm{CF}_{3}$ group 
WILEY-VCH

Sebastián Barata-Vallejo was born in General Villegas (Argentina) and holds degrees in Pharmacy (2007) and Biochemistry (2010). He obtained his Ph.D. degree (2012) at the University of Buenos Aires, studying radical reactions in aqueous and microheterogeneous media under the supervision of Prof. Alberto Postigo. $\mathrm{He}$ has been a research fellow and held several postdoctoral positions at the Istituto per la Sintes Organica e la Fotoreattivita (ISOF), Consiglio Nazionale delle Ricerche (CNR), Bologna, Italia, under the supervision of Dr. C. Chatgilialoglu, studying biomimetic radical reaction and their mechanisms. He is currently a Researcher at the National Council for Scientific and Technical Investigation, CONICET (Argentina), Research Associate at ISOF-CNR, Bologna, Italy, and Lecture at the Organic Chemistry Department, Faculty of Pharmacy and Biochemistry, University of Buenos Aires. His research activities focus on Radical Organic Chemistry, in particular carbon and sulfur centered radicals reactivity.

A1 Postigo was born in Argentina and obtained his M.Sc. degree from University of Buenos Aires in 1986. He moved to Canada in 1990, and obtained his Ph.D. degree from McMaster University in 1994, under the direction of Professor Dr. William J. Leigh. After postdoctoral positions in Canada, he returned to Argentina and worked with Professor Dr. Roberto Rossi at University of Córdoba in the area of radical ion reactions. He held assistant and associate professorship positions at University of Córdoba, University of Buenos Aires, and University of Belgrano. He is currently Full Professor of Organic Chemistry at the Department of Organic Chemistry, Faculty of Pharmacy and Biochemistry, University of Buenos Aires. His interests are in the areas of radical chemistry, both carbon-centered radicals and metal-centered radicals. $\mathrm{He}$ is devoted to studying radical reactions of these species in water and nonconventional media.

\section{2.- Methods and Reagents for Introducing the $\mathrm{CF}_{3}$ Group}
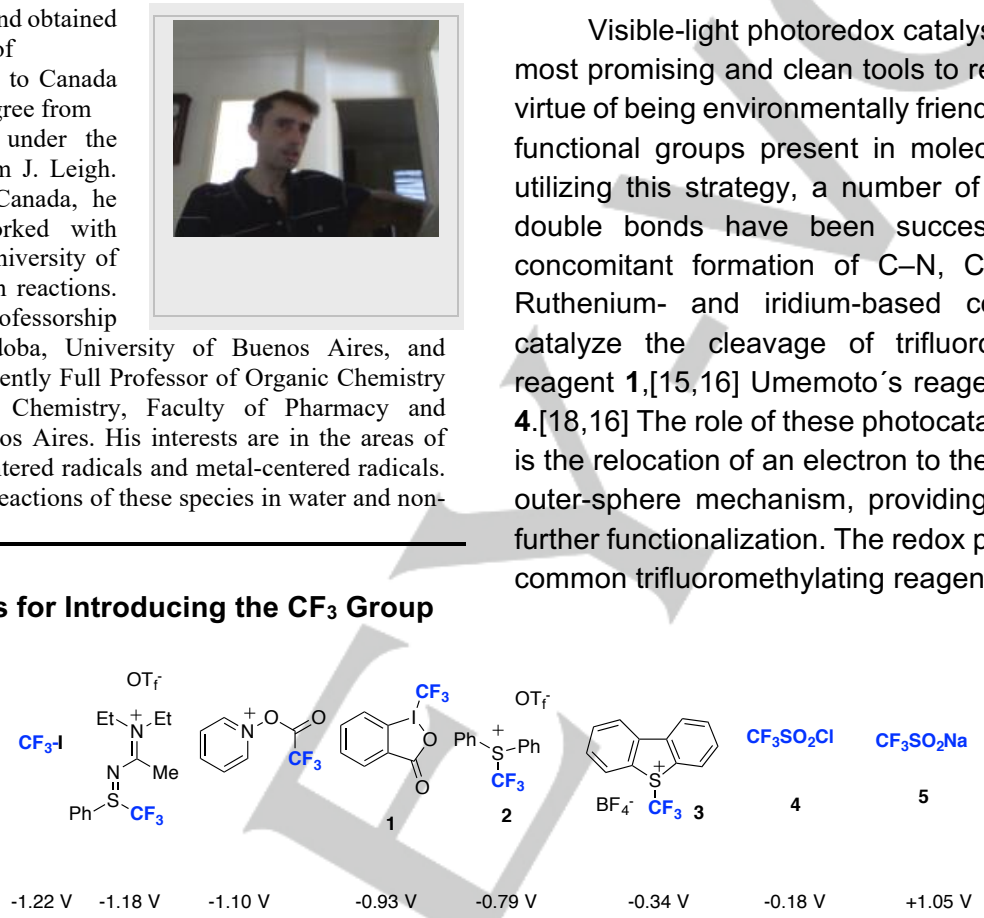

Figure 2. Relevant trifluoromethylating reagents and their redox potentials (vs SCE)

Visible light-trifluoromethylation reactions, frequently associated with Ru-, Ir-, and Pt-complexes as photocatalysts, allow accomplishment of the reactions under efficient conditions (room temperature, good selectivity, and operation simplicity). Several excellent review articles and seminal papers have attested to these processes.[19-23] A recent review article on Ir- and Ruphotocatalyzed trifluoromethylation strategies of multiple bonds and arenes has been presented by Koike and Akita.[23] Only Irand Ru-photocatalyzed trifluoromethylation reactions of carboncarbon multiple bonds that have not been dealt with in previous review articles will be presented in this manuscript.

More recently, organic dye- and all-organic-semiconductor[24] photocatalysts are being employed as metal-free strategies for trifluoromethylation reactions compatible with the requirements of the pharmaceutical industry. Figure 3 shows the most frequently used photocatalysts in trifluoromethylation reactions.
Numerous protocols, including nucleophilic, electrophilic, or radical routes were developed for the incorporation of the $\mathrm{CF}_{3}$ moiety into organic substrates,[11] including examples in which visible-light- mediated redox photocatalysis is employed as key step.[12]

Trifluoromethyl-phosphonium salts $\left(\mathrm{Ph}_{3} \mathrm{P}^{+} \mathrm{CF}_{2} \mathrm{CO}_{2}^{-} / \mathrm{KF}\right)$ have been shown to effect thermal trifluoromethylation reactions of alkynes, aldehydes, ketones, indoline-2,3-diones, and aromatic iodides, and have been reviewed by Zhang.[13] Other trifluoromethylating reagents such as Togni reagent 1, UmemotoYagopulskii 2 , Umemoto reagent 3, triflyl chloride 4, Langlois reagent 5, and $\mathrm{CF}_{3}-\mathrm{I}$ are currently employed in diverse trifluoromethylation strategies (Figure 2).

Visible-light photoredox catalysis is perceived as one of the most promising and clean tools to realize trifluoromethylations in virtue of being environmentally friendly, safe, and tolerant of many functional groups present in molecular scaffolds. In particular, utilizing this strategy, a number of trifluoromethylations of C-C double bonds have been successfully established with the concomitant formation of $\mathrm{C}-\mathrm{N}, \mathrm{C}-\mathrm{O}, \mathrm{C}-\mathrm{X}$ and $\mathrm{C}-\mathrm{S}$ bonds. Ruthenium- and iridium-based complexes can productively catalyze the cleavage of trifluoromethyl iodide,[14] Togni's reagent $1,[15,16]$ Umemoto's reagent $3,[17,16]$ or triflyl chloride 4. $[18,16]$ The role of these photocatalysts in such transformations is the relocation of an electron to the trifluoromethyl source by an outer-sphere mechanism, providing $\mathrm{CF}_{3}$ radicals that ensue in further functionalization. The redox potentials of some of the most common trifluoromethylating reagents are illustrated in Figure 2. 
WILEY-VCH

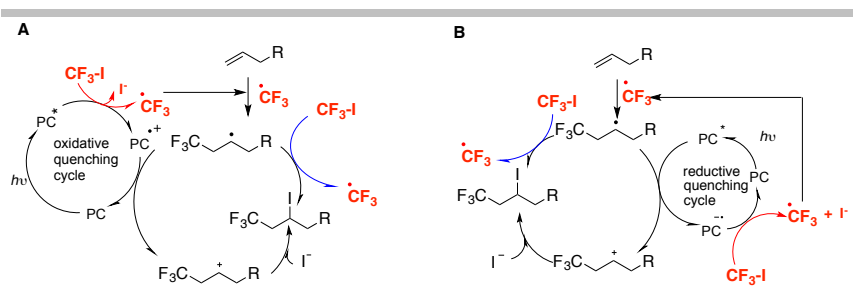

Scheme 1. A. Oxidative and B. Reductive photocatalytic quenching cycles for the trifluoromethylation of alkenes

The details of the initial photochemical activation steps are simple: photoexcitation of $\mathrm{PC}$ produces a long-lived redox-active triplet state $\mathrm{PC}^{*}$ that can be oxidatively quenched by $\mathrm{CF}_{3}-\mathrm{I}$ (Scheme $\left.1 \mathrm{~A}\right)$ or reductively suppressed (Scheme 1B) by a wide range of organic substrates or radical intermediates.

In the oxidative quenching cycle, the $\mathrm{PC}$ is excited and manifests itself as an excellent reductant of $\mathrm{CF}_{3}-\mathrm{I}$, generating $\mathrm{CF}_{3}$ radicals ensuing the $\mathrm{PC}$ in its oxidized upper state. Conversely, in a reductive quenching manner, the visible-light-excited PC accepts an electron either from a sacrificial donor or intermediate, generating the reduced formed of the $\mathrm{PC}\left(\mathrm{PC}^{-}-\right)$, which reduces the $\mathrm{CF}_{3} \mathrm{I}$ to $\mathrm{CF}_{3}$ radical. Trifluoromethylthiolations, trifluoromethylselenolations, and trifluoromethoxylation reactions are not going to be the subjects of this review article, neither trifluoromethylation reactions involving the radioactive isotope ${ }^{18} \mathrm{~F}$

In the next sections, we will show newly-informed (2015present) photocatalyzed trifluoromethylation reactions of carboncarbon multiple bonds and (hetero)aromatic compounds. There are other numerous trifluoromethylation reactions involving other organic group transformations that are not going to be considered in this account, such as the trifluoromethylation of carbonyl compounds, C-N double bonds (enamines, imines, hydrazones, isocyanides), thiols $\mathrm{RSH}$, selenols $\mathrm{RSeH}$. Although this account does not intend to be an exhaust revision of the literature but a discussion on the latest developments (2015-up to now) of photocatalytic trifluoromethylation reactions of (hetero)aromatic compounds and carbon-carbon multiple bonds, all the known photocatalytic strategies will be summarized in Figures 4 and 5 , respectively, in order to guide the reader into selecting proper methods for accomplishing trifluoromethylations of carbon-carbon multiple bonds and (hetero)aromatic compounds and designing new methodologies in photocatalyzed trifluoromethylation processes in view of the newly advanced examples.

\section{2. (Hetero)aromatic substrates}

\section{1.-Photocatalytic Homolytic and Ipso Trifluoromethyl group substitutions of (Hetero)arenes}

Transition metal- catalyzed thermal trifluoromethylation reactions of (hetero)arenes have elegantly been investigated by $\mathrm{Ye}$ and Sanford [11b,25] and summarized in earlier review articles.[26,16] Thermal trifluoromethylation of aromatic iodides with $\mathrm{Ph}_{3} \mathrm{P}^{+} \mathrm{CF}_{2} \mathrm{CO}_{2}^{-}$/ KF has been summarized by Zhang.[13] Electrochemical methods to accomplish trifluoromethylation of arenes have also been informed.[27]

Several photocatalysts and trifluoromethylating reagents have been employed for the $\mathrm{CF}_{3}$-incorporation into (hetero)aromatic substrates (Figure 4). Photocatalyzed $\mathrm{C}_{\text {Het-H }}$ and $\mathrm{C}_{\text {ipso- }} \mathrm{X}$ trifluoromethylations of (hetero)aromatic compounds have been informed with $\mathrm{Ru}(\mathrm{bpy})_{3} \mathrm{Cl}_{2}$ [28-30c] and Ir-photocatalyst $[31,32]$ both with Togni and $\mathrm{CF}_{3}-\mathrm{I}$ reagents. There have been review articles on visible-light-photocatalyzed trifluoromethylation reactions of arenes employing organic dyes [32a-35] and other sensitizers as organic photocatalyst. Figure 4 below summarizes previously reviewed and informed visible-light-photocatalyzed approaches for trifluoromethylation reactions of (hetero)aromatic compounds. The known and reviewed strategies involve organometallic photocatalysts (Figure 4, A) which employ triflic chloride [22,23], Togni reagent,[31,32] $\mathrm{CF}_{3-1,[30 \mathrm{c}, 29] \text { and }}$ Langlois reagent. $[36,37]$ Figure 4 , B, show all the reported nonmetal organo- photocatalysts that make use of the Langlois reagent,[34,35,38-40] triflic chloride,[32,41] Togni reagent,[32,42] and $\mathrm{CF}_{3}-\mathrm{I}[33]$ as sources of $\mathrm{CF}_{3}$ radicals.

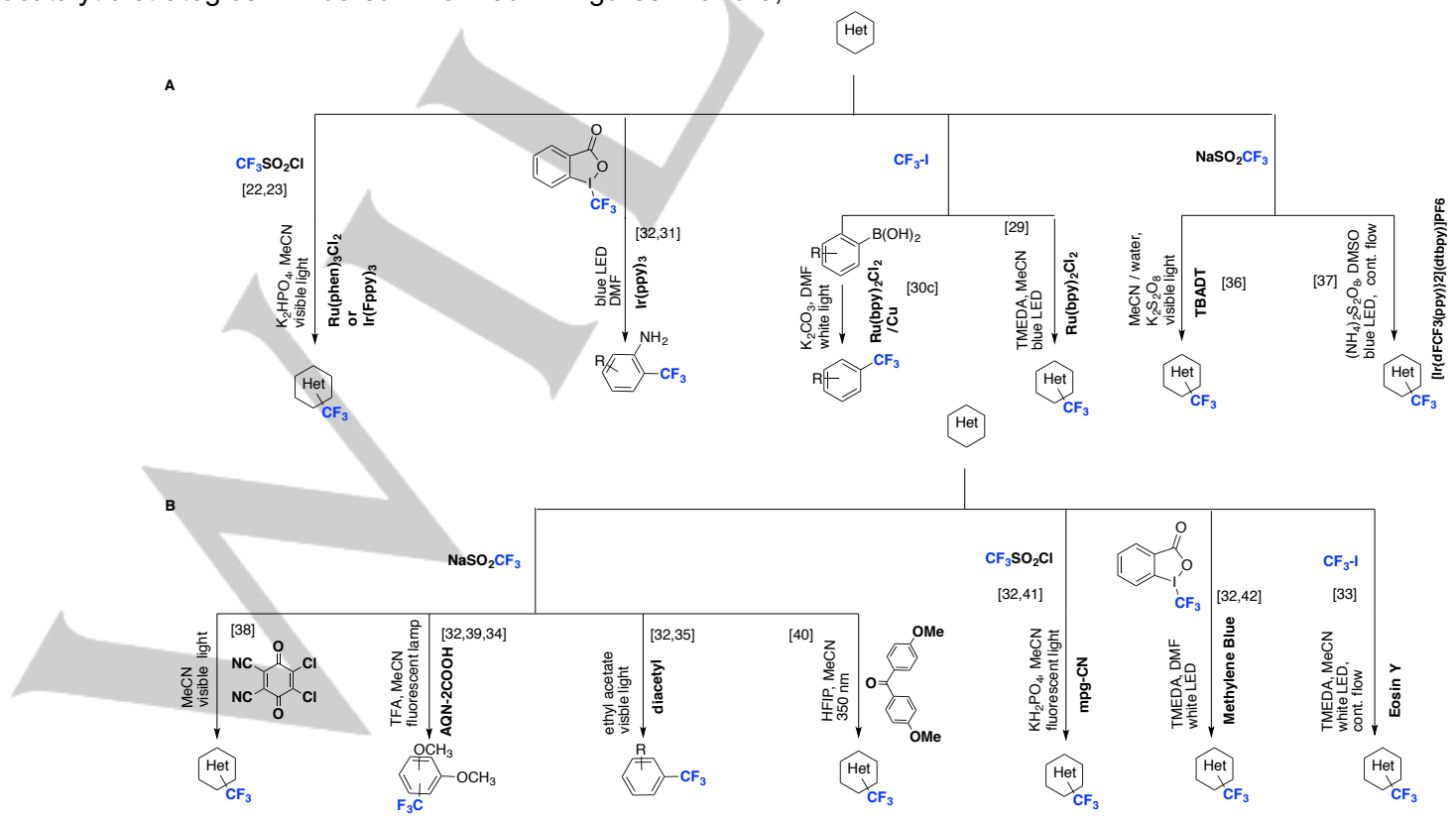


WILEY-VCH

\section{REVIEW}

\section{Figure 4 .}

Trifluoromethylation reactions of (hetero)arenes informed and reviewed in the literature. A.- employing organometallic photocatalysts. B.-employing organic dyes and all-carbon sensitizers

\subsection{2.- New examples on Organo-Photocatalyzed Trifluoromethylations of (Hetero)aromatics}

The first reports on the trifluoromethylation of anilide derivatives photocatalyzed by Eosin $\mathrm{Y}$ with $\mathrm{Cu}(\mathrm{II})$ salts and $\mathrm{Cs}_{2} \mathrm{CO}_{3}$ have been informed by Chen, Tan, Wang and colleagues.[43] A new example on Eosin Y-photocatalyzed trifluoromethylation of arenes is that reported by Tian, $\mathrm{An}, \mathrm{Li}$, and collaborators [44] who studied the trifluoromethylation of anilide derivatives in the ortho$\mathrm{C}-\mathrm{H}$ position by using $\mathrm{CF}_{3} \mathrm{SO}_{2} \mathrm{Na}$ towards the synthesis of trifluoromethyl lactams. The scope of the transformation is succinctly illustrated in Scheme 2.

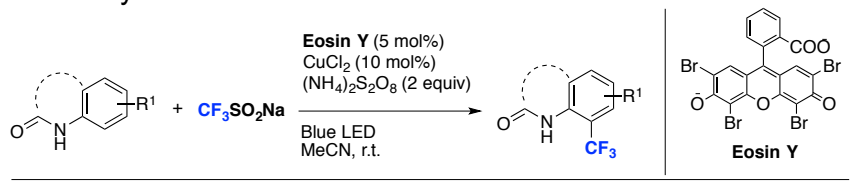

$$
\text { (3) }
$$

Scheme 2. Selected examples for the synthesis of trifluoromethylated lactams.

The authors [44] also attempted a series $N$-phenylbenzamide derivatives and obtained the respective $\mathrm{N}-(2$ (trifluoromethyl)phenyl)benzamides in high to moderate yields.

The authors [44] carried out a sequence of experiments leading to test the mechanism. $\mathrm{N}$-phenylbenzamide, under the standard conditions (Scheme 2$)$, in the presence of TEMPO $((2,2,6,6$ Tetramethylpiperidin-1-yl)oxyl) does not afford the trifluoromethylated $\mathrm{N}$-phenylbenzamide product. The reaction in the presence of 1,1-diphenylethylene (a better radical acceptor) afforded (3,3,3-trifluoroprop-1-ene-1,1-diyl)dibenzene exclusively The reaction of $\mathrm{N}$-(2,6-dimethylphenyl)benzamide (where both alfa positions to the anilide moiety are blocked), afforded no product, purporting that the regioselectivity of substitution is exclusive to the ortho position of the nitrogen atom of the anilide moiety. To explore the role of the $\mathrm{C}-\mathrm{H}$ activation step, a kinetic isotope effect experiment (KIE) was performed. KIE factors found of 1.04 and 1.11 suggest that the $\mathrm{C}-\mathrm{H}$ activation is not the ratedetermining step. The authors [44] proposed a mechanism as illustrated in Scheme $3 a$

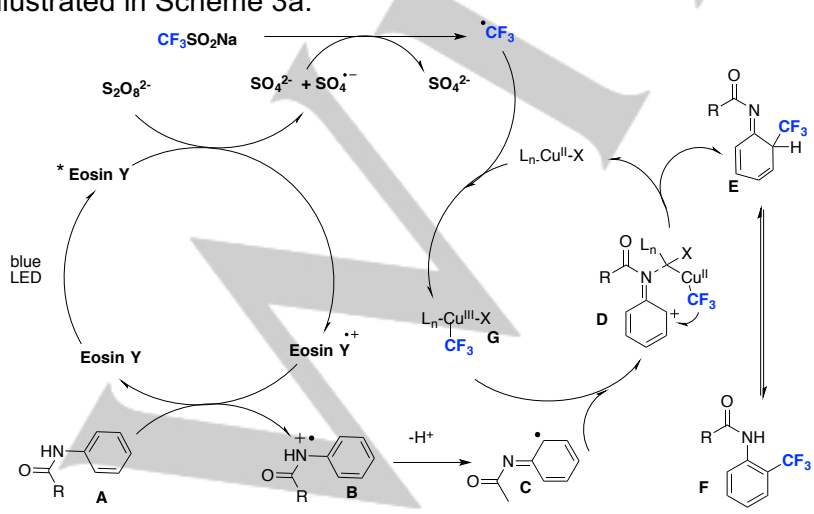

Scheme 3a. Proposed mechanism.
In the proposed mechanism (Scheme 3a) the visible light-excited Eosin $\mathrm{Y}$ reduces the peroxydisulfate to sulfate radical anion $\mathrm{SO}_{4}{ }^{-}$ (and sulfate dianion), which is an excellent oxidant of the Langlois reagent to form $\mathrm{CF}_{3}$ radicals. In turn, the formed radical cation of the photocatalyst accepts an electron from anilide $\mathbf{A}$ to regenerate the photocatalyst into its active state, and produce the radical cation B. Intermediate B is deprotonated to form cyclohexadienyl radical $\mathbf{C}$. From the dual catalytic cycle, the $\mathrm{CF}_{3}$ radical coordinates with $\mathrm{Cu}^{\prime \prime}$ to form complex G. Complex $\mathbf{G}$ (where $\mathrm{Cu}$ is in an upper oxidized state) reacts with intermediate $\mathbf{C}$ to generate complex $\mathbf{D}$, which is attacked intramolecularly by nucleophilic $\mathrm{CF}_{3}$ to render adduct $\mathrm{E}$. After rearrangement, adduct $\mathbf{E}$ affords product $\mathbf{F}$. The authors extended the same protocol to the C5-selective trifluoromethylation of 8-aminoquinolines.[45]

A first and seminal work on methylene-blue- (MB) photocatalyzed trifluoromethylation of heteroaromatics employing Togni reagent 1 was that reported by Scaiano and colleagues who gave relevant spectroscopic and kinetic data throwing light on the mechanism of the MB-photocatalyzed trifluoromethylation of indoles, pyrroles, and thiophene derivatives (Scheme 3b).[46]

$$
\text { (2) }
$$

Scheme 3b. Selected examples for the methylene-blue photocatalyzed trifluoromethylation of heteroarenes

A recent visible-light-promoted $\mathrm{C}_{3}-\mathrm{H}$ trifluoromethylation of $2 \mathrm{H}$-indazoles catalyzed by methylene blue under metal-free conditions has been informed by Bakthadoss, Sharada and colleagues.[47a] The photocatalyst used is methylene blue MB, PIDA (phenyliodine(III) diacetate) as the oxidant, $\mathrm{NaSO}_{2} \mathrm{CF}_{3}$ as source of $\mathrm{CF}_{3}$ radicals, in $\mathrm{DCM}$ as solvent, irradiating with a compact fluorescent lamp. A summary of the scope of the transformation is illustrated in Scheme 4.
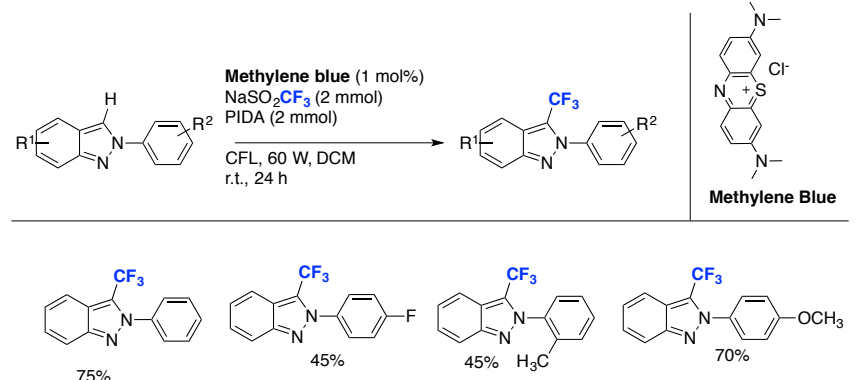

Scheme 4. Selected examples for the trifluoromethylation of $2 \mathrm{H}$-indazoles.

The authors [47a] proposed a mechanism such as that shown in Scheme $5 a$. 
WILEY-VCH

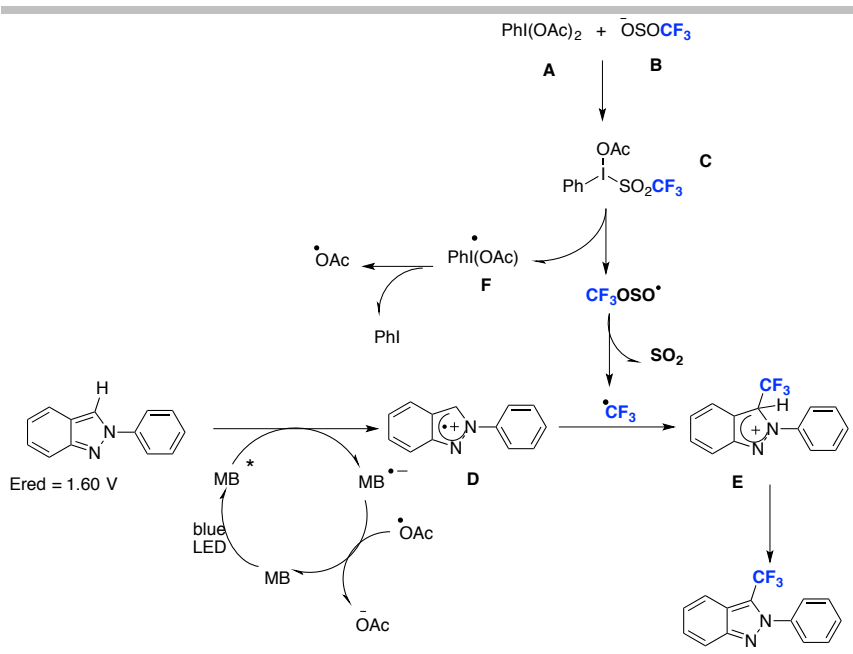

Scheme 5a. Proposed reaction mechanism for the MB-photocatalyzed trifluoromethylation of $2 \mathrm{H}$-indazoles.

To commence with, the reaction of $\mathrm{NaSO}_{2} \mathrm{CF}_{3}$ with PIDA via intermediate $\mathrm{C}$ generates the $\mathrm{CF}_{3}$ radical. Upon visible light absorption, methylene blue $(M B)$ is excited to $M^{*}$ which by reaction with indazole produces the indazole radical cation $\mathbf{D}$ with the concomitant generation of radical anion $\mathrm{MB}^{\circ-}$. Thermoneutral $\mathrm{MB}$ is regenerated from $\mathrm{MB}^{--}$through a single electron transfer (SET) process by reducing acetate radical to acetate anion. Then, the generated $\mathrm{CF}_{3}$ radical would attack intermediate $\mathbf{D}$ to form intermediate $\mathbf{E}$, which upon deprotonation would result in the trifluoromethylation product. In the mechanism proposed by the authors, [47a] the encounter of two short-lived intermediates (D and $\mathrm{CF}_{3}$ radicals) represent a key step that leads to the formation of the final product.

Zhang and collaborators [47b] developed a photoredox transition-metal-free regioselective $\mathrm{C}-\mathrm{H}$ trifluoromethylation of imidazopyridines employing $\mathrm{CF}_{3} \mathrm{SO}_{2} \mathrm{Na}$ (Langlois reagent) as ' $\mathrm{CF}_{3}$ radical source, anthraquinone-2-carboxylic acid (AQN-2$\mathrm{CO}_{2} \mathrm{H}$ ) as photocatalyst, $\mathrm{K}_{2} \mathrm{CO}_{3}$ as base, trifluoroacetic acid as additive, DMSO as solvent, under $\mathrm{N}_{2}$ atmosphere and irradiating with blue LEDs. The reaction proved to be useful with a range of substituted imidazopyridines (Scheme $5 \mathrm{~b}$ ). The authors [47b] evoke a reaction mechanism initiated by irradiation of the photocatalyst to yield $\left[\mathrm{AQN}-2-\mathrm{CO}_{2} \mathrm{H}\right]^{*}$ that further undergoes a single electron transfer process with $\mathrm{CF}_{3} \mathrm{SO}_{2} \mathrm{Na}$ to afford ${ }^{\circ} \mathrm{CF}_{3}$ radicals, $\mathrm{SO}_{2}$ and $\left[\mathrm{AQN}-2-\mathrm{CO}_{2} \mathrm{H}\right]{ }^{-}$. The authors propose the reaction of $\mathrm{SO}_{2}$ with $\left[\mathrm{AQN}-2-\mathrm{CO}_{2} \mathrm{H}\right]^{-}$to regenerate the photocatalyst $A Q N-2-C_{2} \mathrm{H}$. The ${ }^{\circ} \mathrm{CF}_{3}$ radicals react with the substrate to generate radical adduct $\mathbf{A}$ that, according to the proposal, is oxidized by other ${ }^{\circ} \mathrm{CF}_{3}$ radical to the carbocationic intermediate $\mathbf{B}$ that upon deprotonation yields the reaction product (Scheme 5c).

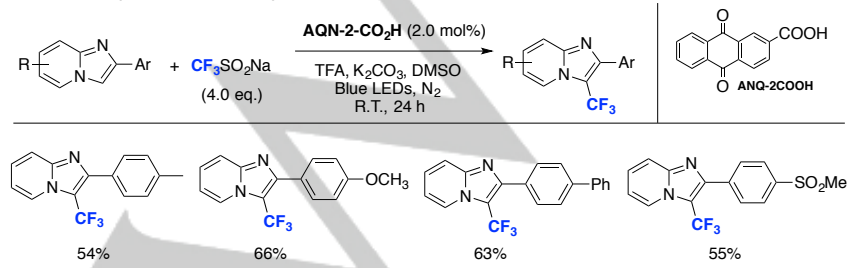

Scheme $\mathbf{5 b}$. Selected examples of transition-metal-free, visible light mediated regioselective $\mathrm{C}-\mathrm{H}$ trifluoromethylation of imidazopyridines.

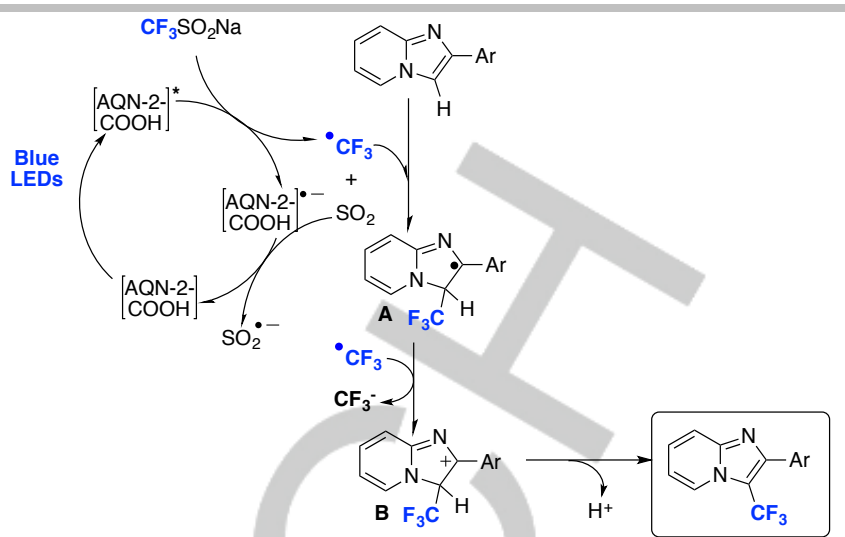

Scheme 5c. Proposed reaction mechanism for the transition-metal-free, visible light mediated regioselective $\mathrm{C}-\mathrm{H}$ trifluoromethylation of imidazopyridines.

The use of flow chemistry [48a,b] in photocatalytic reactions is particularly beneficial as reaction times are decreased as a consequence of the small dimensions of microreactors which permits a vast absorption of incident photons by a homogeneous irradiation of the total reaction, allowing shorter residence times, and lower amounts of photocatalysts needed. A crucial advantage of microflow reactions is when a gaseous reagent is used.[48c] In this latter case, the mixing of liquid and gas reagents provides enhanced mixing, increasing mass transfer in a segmented flow regime.[48d]

Bottecchia, Nöel, and colleagues [48e] have informed the room-temperature trifluoromethylation of (hetero)aromatic compounds employing 5,5'-bis((2(trifluoromethyl)phenyl)ethynyl)-2,2'-bithiophene as photocatalyst (see Scheme 6a for PC structure), and gaseous $\mathrm{CF}_{3} \mathrm{l}$ as trifluoromethyl source, $N, N, N^{\prime}, N^{\prime}$-tetramethylethylenediamine (TMEDA) as base, DMF as solvent irradiating with a blue LED under flow system.

DFT calculations were used to predict a priori the spectroscopic properties and the redox potentials of an array of molecules that would be suitable for the transformation, among which, 5,5'-bis((2-(trifluoromethyl)phenyl)ethynyl)-2,2'bithiophene resulted as the best choice. The activity of the tested compounds used as PCs was comparable with that of other commonly employed organic- or transition-metal- photocatalysts (i.e. 5,5'-bis(phenylethynyl)-2,2'-bithiophene (Th-BT-Th) and $\mathrm{Ru}(\mathrm{bpy}) 3^{2+}$ ), obtaining a series of $\mathrm{CF}_{3}$-derivatives in good to excellent yields. The scope of the transformation is succinctly depicted in Scheme 6a.
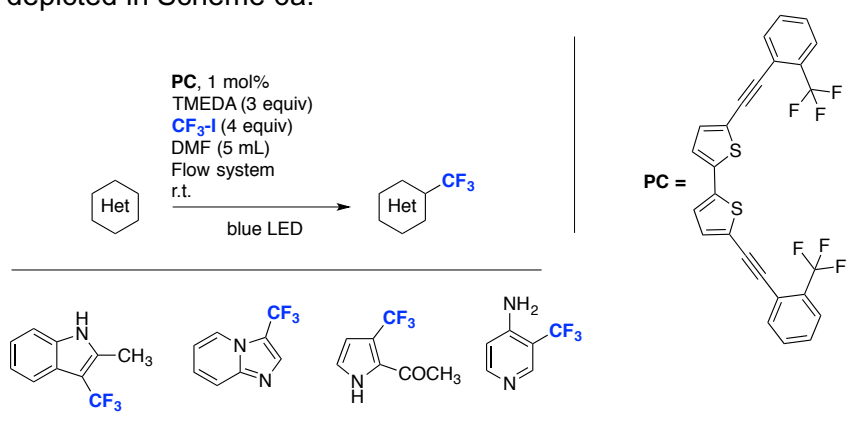

$51 \%$

$29 \%$

$56 \%$

$26 \%$

Scheme 6a. Photocatalytic trifluoromethylation of heteroarenes employing 5,5'-bis((2-(trifluoromethyl)phenyl)ethynyl)-2,2'-bithiophene photocatalyst, and $\mathrm{CF}_{3} \mathrm{l}$ as trifluoromethyl source. 
WILEY-VCH

Fluorescence quenching studies on the reactions demonstrated that both reductive and oxidative single electron transfers (SET) are viable pathways for the excited state of photocatalyst PC. Such versatility in terms of redox properties further highlights the potential of this novel photocatalyst series in a broad range of photocatalytic reactions.

Cambié, Nöel and colleagues [48f] have recently introduced the use of luminescence solar concentrator photomicroreactors (LSC-PMs) [48g] (which are made of a polymeric material such as perfluoroalkoxy alkane capillaries embedded with poly(methylmethacrylate) lightguides and a photocatalyst such as $\mathrm{Ru}(\mathrm{bpy})_{3} \mathrm{Cl}_{2}$ ) for the trifluoromethylation of mesitylene. These LSCs use solar light that harvest and concentrate solar photons. Although there is a single example presented for a LSC-PMs trifluoromethylation reaction of an aromatic compound, the contribution [48f] has a great potential for the trifluoromethylation of numerous families of organic substrates. Scheme $6 \mathrm{~b}$ illustrates the case study.

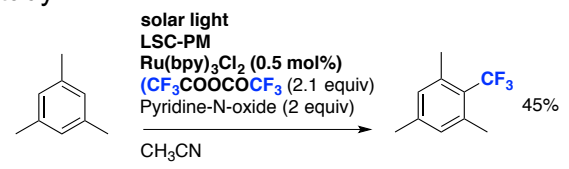

Scheme 6b. LSC-PM trifluoromethylation reaction of mesitylene employing embedded $\mathrm{Ru}(\mathrm{bpy})_{3} \mathrm{Cl}_{2}$ photocatalyst

A new copper-based photoredox-catalyzed cross-coupling of aryl thianthrenium salts with a trifluoromethyl reagent has recently been reported by $\mathrm{Ye}$, Ritter, and colleagues [49a] to facilitate a site-selective late-stage trifluoromethylation of arenes. The method first entails the $\mathrm{C}-\mathrm{H}$ thianthrenation using thianthrene-S- oxide, TFAA, and $\mathrm{HBF}_{4}-\mathrm{Et}_{2} \mathrm{O}$ and later, the $\mathrm{Ru}(\mathrm{bpy})_{3}\left(\mathrm{PF}_{6}\right)_{2}$-visible light photocatalyzed (blue LED) trifluoromethylation, employing $\mathrm{CuCF}_{3}$ as source of $\mathrm{CF}_{3}$ radicals, in $\mathrm{MeCN}$ as solvent. The scope of the transformation is succinctly depicted in Scheme $7 a$.
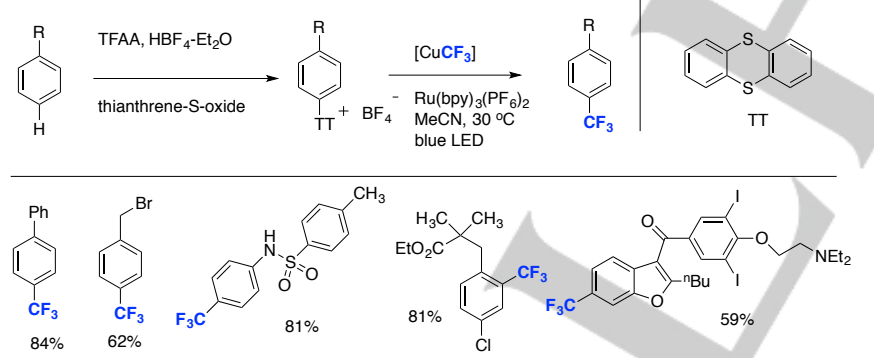

Scheme 7a. Selected examples for the site-selective trifluoromethylation of arenes.

Preliminary mechanistic experiments of the photoredox trifluoromethylation show that the photoexcited $\mathrm{Ru}(\mathrm{II})$-catalyst is quenched faster by the $\left[\mathrm{CuCF}_{3}\right]$ reagent than the arylthianthrenium salt (by Stern-Volmer analysis). Adding 0.5 equiv of TEMPO, the yield of $4-\mathrm{CF}_{3}$-chlorobenzene was only $6 \%$ lower than that without the addition of TEMPO, and TEMPO- $\mathrm{CF}_{3}$ was detected in less than $5 \%$. These results indicate that $\mathrm{CF}_{3}$ radical may not be involved in the trifluoromethylation pathway.

Díaz Díaz and collaborators [49b] have presented a photocatalyzed trifluoromethylation strategy for electron-rich and electron-deficient aromatic compounds in gel media. The reactions are performed with a low-molecular-weight (LMW) gelator $\mathbf{G 1}$ (see Scheme $7 \mathrm{~b}$ ), employing $\mathrm{CISO}_{2} \mathrm{CF}_{3}$ as ${ }^{\circ} \mathrm{CF}_{3}$ source, $\mathrm{Ru}(\mathrm{phe})_{3} \mathrm{Cl}_{2}$ or $\operatorname{Ir}(\mathrm{ppy})_{3}$ as photocatalyst in acetonitrile, under aerated conditions and upon illumination, affording yields of trifluoromethylated products (Scheme $7 \mathrm{~b}$ ) similar to those obtained in solution under inert atmosphere.[49b]

A metal-free strategy for the trifluoromethylation of 1,3,5trimethoxybenzene employing sodium triflinate as ${ }^{\circ} \mathrm{CF}_{3}$ radical source has also been successfully explored.[49b] The reaction afforded full conversion when gelator $\mathbf{G 1}$ (see Scheme $7 \mathrm{~b}$ ) was employed, yielding the mono- $\mathrm{CF}_{3}$ and di-CF 3 substituted products in 13:1 ratio, respectively.[49b]

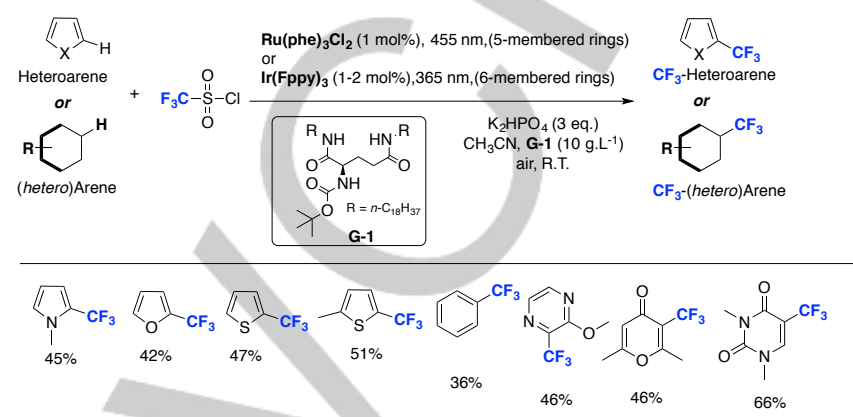

Scheme $\mathbf{7 b}$. Selected examples of intragel trifluoromethylation of 5- and 6-membered (hetero)arenes.

Duan and collaborators [49c] have developed a photocatalytic methodology for direct trifluoromethylation of aromatics at metabolically relevant positions in the absence of any directing groups. The authors [49c] have achieved a novel coordination polymer based on triphenylamine (TPA) by inserting thiophene moieties into the TPA-based ligand, allowing the synthesis of Zn-TCTA (Zn-tris[4-(5-carboxy-2thienyl)phenyl]amine) which is used as photocatalyst and ligand. This modification improves the light harvesting ability of the ligand by enlarging the conjugation of the $\pi$-system, and also distorts the geometries of the metal nodes allowing substrates to be anchored near the photo-redox active centers. This methodology allows regio- and diastereoselective discrimination between similar reactive sites within the substrates (Scheme 7c).

(hetero)Arene

Scheme 7c. Selected examples of the photocatalytic trifluoromethylation of aromatics mediated by $\mathrm{Zn}$-TCTA.

\subsection{3.-New examples on the Use of Semiconductors for Trifluoromethylations of (Hetero)aromatic Compounds}

Organic semiconductors are considered chemically inert towards $\mathrm{Csp}{ }^{3}$ radicals and nucleophiles, having a convenient bandgap between valence band maxima and conduction band minima. This contrasts with standard photocatalysts such as $\mathrm{fac}-\operatorname{Ir}(\mathrm{ppy})_{3}$, which react with $\mathrm{Csp} p^{3}$ radicals, or Eosin $\mathrm{Y}$ which varies its activity with $\mathrm{pH}$.

Ghosh, Antonietti, König and colleagues [24] have recently reported the use of an organic semiconductor, mesoporous 
WILEY-VCH

graphitic carbon nitride (mpg-CN [41]), which can trigger two reactants in one-photonic-process, by suppressing an excited electron and a residual positive hole. This novel approach is markedly different from that of ordinary photocatalysts which typically react with a single reactant either through oxidation or reduction. In this way, the authors [24] effect the substitution of two carbon-hydrogen bonds of arenes and heteroarenes. The $m p g-C N$ has an available redox window of $2.7 \mathrm{~V}$ (from $+1.2 \mathrm{~V}$ to $-1.5 \mathrm{~V}$ versus saturated calomel electrode (SCE) upon 460-nm illumination), which translates into a considerable versatility as photocatalyst system.

The authors [24] distinguish two distinct and general ways of operation for semiconductor photocatalysts: $i$.- a type A process is when the substrate activation (oxidation or reduction, hole or electron, respectively) leads to monofunctionalized arene products ; ii.- the reactions are designated as type B' and type $B^{\prime \prime}$ when the hole and electron on the surface of the catalyst perform both oxidative and reductive redox steps to yield arene products substituted at two different $\mathrm{C}-\mathrm{H}$ sites from more than either two or three reagents. For these latter types of transformations, the scope of the methodology using $m p g-C N$ is briefly illustrated in Scheme 8.

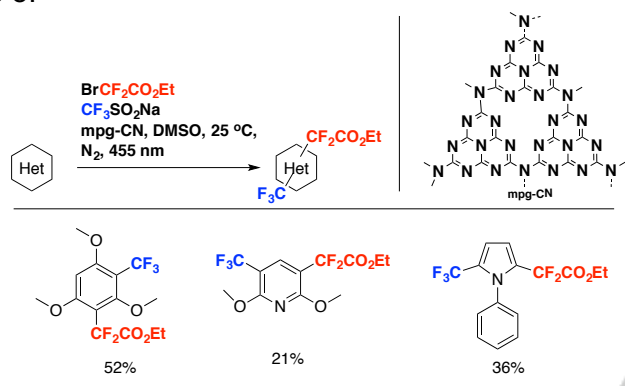

Scheme 8. Semiconductor photoredox catalytic arene C-H trifluoromethyl and difluoromethyl biofunctionalization.

When mpg-CN is photoexcited produces electron and hole pairs that can effect such biofunctionalizations, with catalyst recoverability and reuse as a practical advantage. Two different $\mathrm{C}\left(s p^{3}\right)$-centered radicals accessed through oxidative (from $\mathrm{CF}_{3} \mathrm{SO}_{2} \mathrm{Na}$ ) and reductive (from $\mathrm{BrCF}_{2} \mathrm{CO}_{2} \mathrm{Et}$ ) photoredox transformations are realized. Sodium triflinate has an redox potential of approximately $+1.1 \mathrm{~V}$ (versus SCE) and is oxidized by photoexcited mpg- $\mathrm{CN}$, generating the $\mathrm{CF}_{3}$ radicals. Analogously, $\mathrm{BrCF}_{2} \mathrm{CO}_{2} \mathrm{Et}$ is reduced to $\mathrm{CF}_{2} \mathrm{CO}_{2} \mathrm{Et}$ radicals. In typical semiconductor-type $\mathrm{B}$ photocatalysis there is a recombination of redox intermediates (radicals or radical ions) that are generated by oxidative and reductive redox steps to give coupled endproducts. In the process described by Koenig et al [24] (type B") two redox intermediates react with one arene to form two new chemical bonds.

The system proposed [24] can also effect type A reactions. Although this latter approach had been explored before the current protocol [24] by Blechert and colleagues, [41] the present methodology [24] employs the Langlois reagent instead of the triflic chloride.[41] Selected examples for trifluoromethylations of (hetero)arenes are illustrated in Scheme 9.

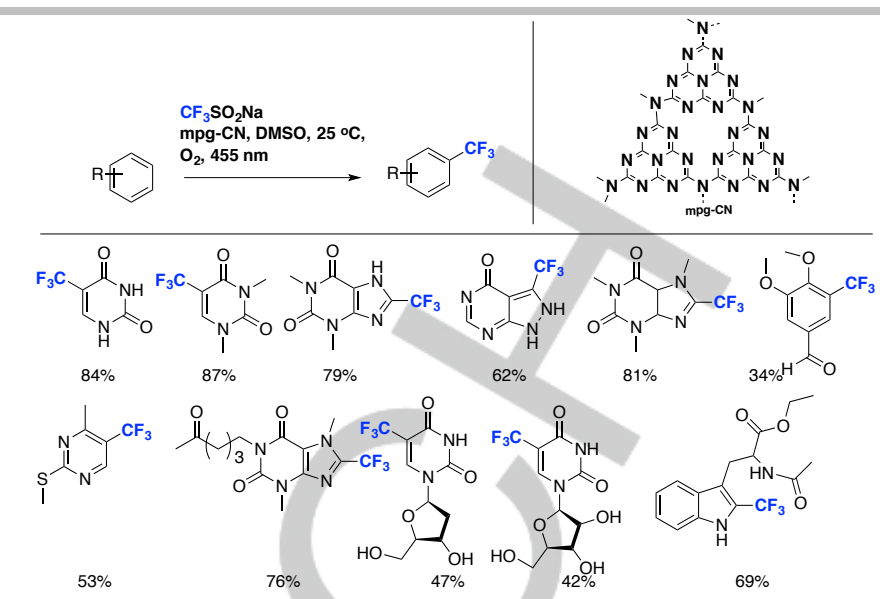

Scheme 9. Selected examples for the mpg-CN-photocatalyzed trifluoromethylation of biologically-relevant heteroarenes.

Most of the photoredox catalysts used for trifluoromethylation are not capable of generating the $\mathrm{CF}_{3} \cdot$ radical from $\mathrm{CF}_{3} \mathrm{CO}_{2} \mathrm{Na}$ (which would be the most economical source of $\mathrm{CF}_{3}$ radicals), because of its high oxidation potential $\left(\mathrm{E}_{1 / 2}=\right.$ 1.6-2.46 V).[22] Research has been carried out in order to improve the photocatalytic performance of $\mathrm{ZnO}$ as semiconductor photocatalyst. One approach is to load Au nanoparticles on the surface of $\mathrm{ZnO}$ nanostructures. Owing to localized surface plasmon resonance (LSPR), gold ( $\mathrm{Au}$ ) placed on semiconductorbased photocatalysts shows strong visible light absorption characteristics.[50,51]

Bazyar and Hosseini-Sarvari [52] recently reported a new simple trifluoromethylation reaction using $\mathrm{CF}_{3} \mathrm{CO}_{2} \mathrm{Na}$ as source of $\mathrm{CF}_{3}$ radicals and $\mathrm{Au}$-modified $\mathrm{ZnO}$ as a photocatalyst under visible light irradiation. The reaction can employ of a broad range of aryl halides, arylboronic acids, and arene and heteroarene substrates. The scope of the transformation is succinctly illustrated in Scheme 10.
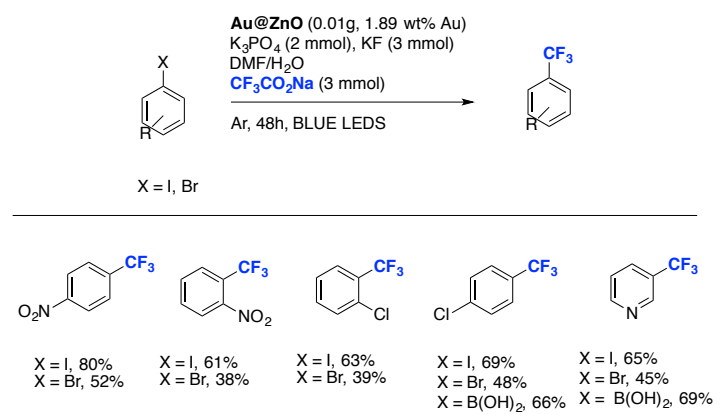

Scheme 10. Selected examples for the scope of the trifluoromethylation using sodium trifluoroacetate as a reagent and Au-modified $\mathrm{ZnO}$ as a photocatalyst under visible light irradiation.

The authors [52] next studied the direct $\mathrm{C}-\mathrm{H}$ functionalization of activated and nonactivated (hetero)arenes with $\mathrm{Au@ZnO} \mathrm{core-shell} \mathrm{nanoparticles} \mathrm{as} \mathrm{a} \mathrm{photocatalyst} \mathrm{and}$ $\mathrm{CF}_{3} \mathrm{CO}_{2} \mathrm{Na}$ as a trifluoromethylation reagent. For aromatic homolytic substitutions, an external oxidant was needed. In this case, the employment of $\mathrm{K}_{2} \mathrm{~S}_{2} \mathrm{O}_{8}$ seemed suitable to effect the trifluoromethylation of heteroarenes in good yields. A brief scope of the transformation is summarized in Scheme 11. 
WILEY-VCH

$\mathrm{Au@ZnO}(0.02 \mathrm{~g}, 1.89 \mathrm{wt} \% \mathrm{Au})$
$\mathrm{K}_{2} \mathrm{~S}_{2} \mathrm{O}_{8}(1.5 \mathrm{mmol}), \mathrm{KF}(3 \mathrm{mmol})$
$\mathrm{DMF}^{2} \mathrm{H}_{2} \mathrm{O}$

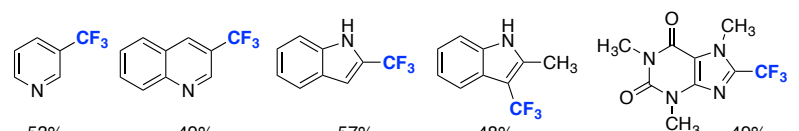

Scheme 11. Selected examples for the homolytic aromatic substitution of heteroarenes.

Addition of triethanolamine and ammonium oxalate (hole $(\mathrm{h}+)$ scavengers) gave only trace of product. When radical scavenger TEMPO was added into the reaction mixture, it formed the TEMPO- $\mathrm{CF}_{3}$ adduct quantitatively confirmed by ${ }^{19} \mathrm{~F}$ NMR spectroscopy. Based on the above and other control experiments, the authors [52] proposed a reaction mechanism such as that depicted in Scheme 12.

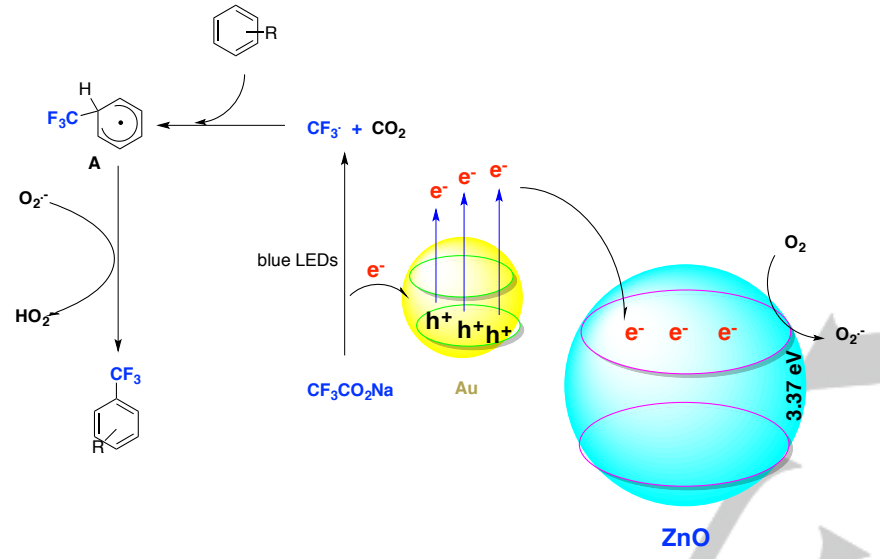

Scheme 12. Proposed reaction mechanism for the use of Au-modified $\mathrm{ZnO}$ as a photocatalyst under visible light irradiation.

In the mechanism proposed (Scheme 12), blue LEDirradiation of $\mathrm{CF}_{3} \mathrm{CO}_{2} \mathrm{Na}$ leads to reduction of hole from the $\mathrm{Au}$ nanoparticle, producing in turn $\mathrm{CF}_{3}$ radicals, which add to the (hetero)arene producing a cyclohexadienyl- $\mathrm{CF}_{3}$-substituted radical. The electron deposited on the conduction band of the $\mathrm{Au}$ nanoparticle is transferred to the $\mathrm{ZnO}$ surface which reduces oxygen to anion superoxide, responsible for the hydrogen abstraction from the radical adduct $\mathbf{A}$, to re-aromatize the ring, yielding the thermoneutral $\mathrm{CF}_{3}$-substituted product.

Tong, Xu, Yuan and collaborators [53] have recently reported that graphene oxide (GO) sheets can photocatalyze the trifluoromethylation of arenes as an all-carbon-metal-free photocatalyst, using the inexpensive Langlois reagent as the $\mathrm{CF}_{3}$ radical source. The authors achieve substitutions with the $\mathrm{CF}_{3}$ moiety onto mono-substituted benzene derivatives such as toluene, benzaldehyde, anisole, methylbenzoate, o-xylene, nitrobenzene and $p$-chlorotoluene. Although low regioselectivity for the $\mathrm{CF}_{3}$-substitutions are obtained, the yields reported are moderate. In this way, the authors [53] show that carbonaceous photocatalysts possess favorable applicability in such chemical reactions. Although the synthetic applicability of the protocol has not been widely explored by the authors,[53] an apparent advantage presented over the Au@ZnO [52] system, is that no external oxidant is employed to achieve HAS with the $\mathrm{CF}_{3}$ moiety.

Mechanistically, the authors [53] noted that the oxidation potential of $\mathrm{h}^{+}$in these excited $\mathrm{GO}$ photocatalysts $(1.5 \mathrm{eV})$ is much higher than that of ${ }^{\circ} \mathrm{CF}_{3} / \mathrm{CF}_{3} \mathrm{SO}_{2}$; ; this fact will preferentially lead to the formation of ${ }^{\circ} \mathrm{CF}_{3}$ active species (which effects substitution) rather the production of $h^{+}$.

\section{3.-Photocatalytic Trifluoromethylation Alkenes}

The trifluoromethylation of alkenes has been dealt with in the past in different review articles approaching the study from different perspectives.[16,54,55] For instance, the photocatalyzed trifluoromethylation of internal alkenes with sodium triflinate $\left(\mathrm{CF}_{3} \mathrm{SO}_{2} \mathrm{Na}\right)$ employing different photocatalysts such as mesityl acridinium tetrafluoro borate, bis(4-methoxyphenyl)methanone, and/or Ir -based photocatalyst has been reviewed by Lefebvre.[34] Photocatalytic trifluoromethylation of electrondeficient alkenes has been achieved by Lefebvre, Hoffmann and Rueping [40] also with the Langlois reagent as $\mathrm{CF}_{3}$ source and readily accessible benzophenone derivatives as photosensitizers in batch and flow.

Oh, Han, and colleagues [55] have presented a review article where trifluoromethylation strategies of multiple bonds are classified according to the trifluoromethylating reagent $\left(\mathrm{CF}_{3} \mathrm{SO}_{2} \mathrm{Cl}\right.$, $\mathrm{CF}_{3} \mathrm{l}, \mathrm{CF}_{3} \mathrm{SO}_{2} \mathrm{Na}$, Togni reagent, Umemoto's reagent). Some of these strategies are photocatalyzed in nature. Other review articles on trifluoromethylation of multiple bonds combine an array of trifluoromethylating reagents, both activated by thermal and photochemical methods.[56] The use of iridium- and rutheniumbased photocatalysts for trifluoromethylations of multiple bonds has been reviewed by Koike and Akita.[57]

Figure 5 shows trifluoromethylation reactions of alkenes and alkynes involving Ru- and Ir- photocatalysts, which have been discussed in preview review articles.[16] An excellent and more recent account for the Ru- and Ir-photocatalyzed trifluoromethylation of carbon-carbon multiple bonds [23] has been illustrated by Koike and Akita. The authors [23] show Ir- and Ru-photocatalyzed trifluoromethylation (and difluoromethylation) reactions of multiple bonds employing the Umemoto's reagent, the Yagupolskii-Umemoto reagent $\left(\mathrm{PhS}\left(\mathrm{CF}_{3}\right) \mathrm{Ph}^{+}{ }^{-} \mathrm{OT}_{\mathrm{f}}\right)$, and the Togni reagent. In these latter accounts $[57,23]$ the simultaneous introduction of $\mathrm{CF}_{3}$ and $\mathrm{OR}, \mathrm{NR}_{2}$, and Nu groups are discussed. 
WILEY-VCH

$$
\text { A }
$$

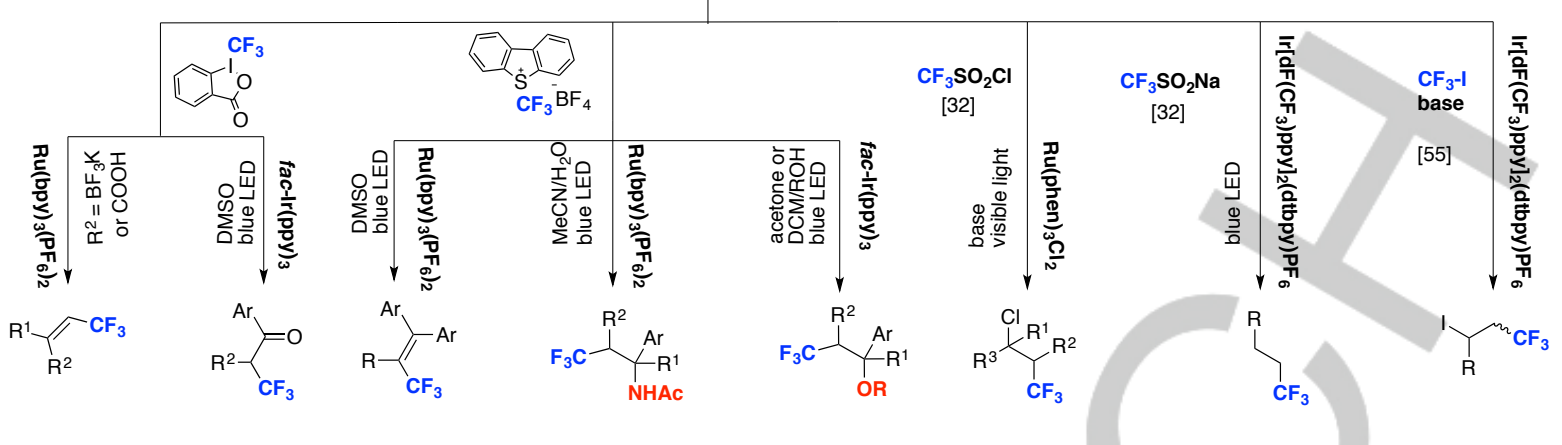

B

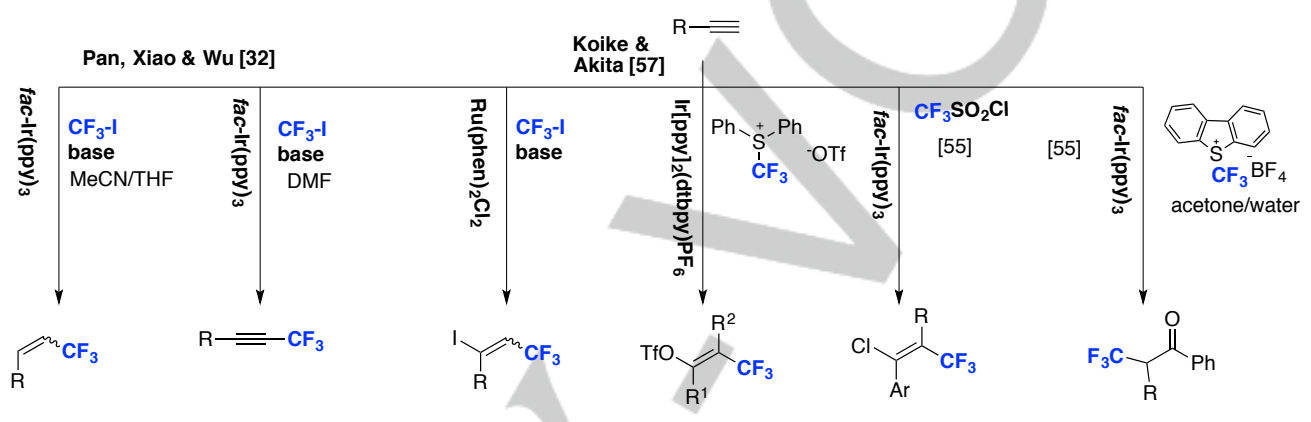

Figure 5. Transition-metal-photocatalyzed trifluoromethylations of alkenes and alkyne

The authors investigated the reaction mechanism, and made the following proposal illustrated in Scheme 14. Firstly, the photocatalyst $\mathrm{Ru}(\mathrm{bpy}) 3^{2+}$ is excited by means of visible light from

As illustrated in Figure $5 \mathbf{A}$, the known reported strategies for Iror Ru-photocatalyzed trifluoromethylation reactions of carboncarbon double bonds make use of Togni reagent,[57] Umemoto reagent,[57] triflic chloride,[32] Langlois reagent,[32] and $\mathrm{CF}_{3} \mathrm{I}$ as sources of $\mathrm{CF}_{3}$ radicals.[55] The organometal-photocatalyzed trifluoromethylation strategies of alkynes can use different

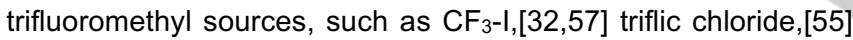
Umemoto reagent,[55] and Umemoto-Yagupolskii reagent (Figure 5 B).[57]

We will next illustrate a general organometalphotocatalyzed strategy [58] for the Ru-photocatalyzed trifluoromethylation of allylic positions employing the Umemoto's reagent, $\mathrm{Ru}(\mathrm{bpy})_{3} \mathrm{PF}_{6}$ as $\mathrm{PC}$, in $\mathrm{DMSO}$ as solvent, irradiating with $425 \mathrm{~nm}$ blue LEDs, with 2,6-ditert-butylpyridine as base. The scope of the transformation is illustrated in Scheme 13.

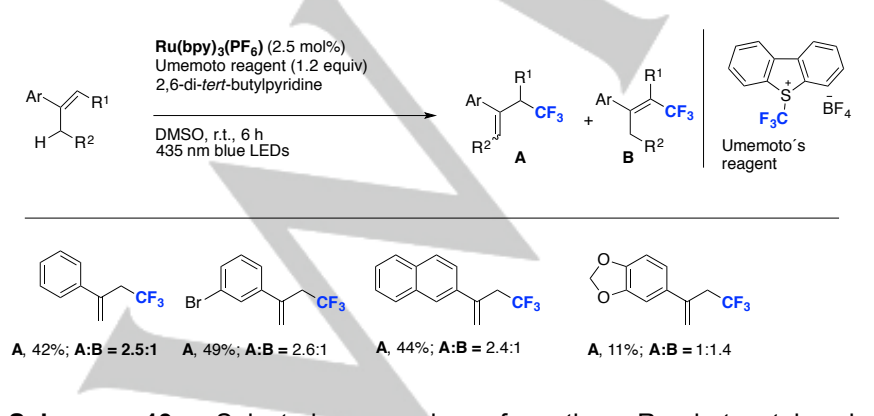

Scheme 13. Selected examples for the Ru-photocatalyzed trifluoromethylation of allylic positions. blue LEDs, generating an excited photocatalyst, which is a strong reductant of Umemoto's reagent to produce trifluoromethyl radicals, which add to the olefinic position of the styryl derivative to afford the benzyl-type radical $\mathbf{C}$ and the oxidized PC (i.e.: $\mathrm{Ru}(\mathrm{bpy}) 3^{3+}$ ). Radical $\mathbf{C}$ is in turn oxidized by the upper oxidation state of the Ru photocatalyst, generating the benzyl cation $\mathbf{D}$ and the photocatalyst in the lower oxidation state. Intermediate D undergoes a base-induced deprotonation to afford the trifluoromethylated allylic product.

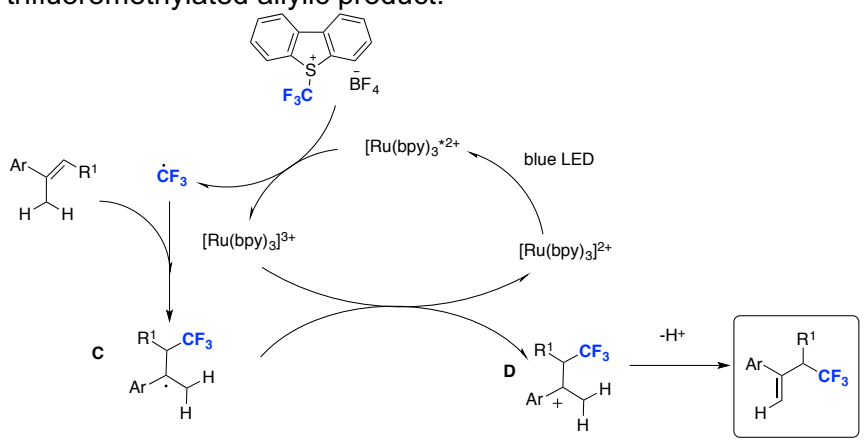

Scheme 14. Proposed reaction mechanism for the Ru-photocatalyzed allylic trifluoromethylation of alkenes.

Sureshkumar and colleagues [59] have recently reported on the photocatalyzed trifluoromethylation of $p$-quinone methides employing $\mathrm{T}\left(p-\mathrm{CH}_{3}\right) \mathrm{PPT} \quad$ (i.e.:2,4,6-tris(paramethylphenyl)pyrilium tetrafluoroborate, see Figure 3 for PC structure) as photocatalyst, the Langlois reagent as source of 
WILEY-VCH

\section{REVIEW}

trifluoromethyl radicals, in $\mathrm{MeCN}$ as solvent, irradiating with blue LEDs. Selected examples of the scope of the method is illustrated in Scheme 15.

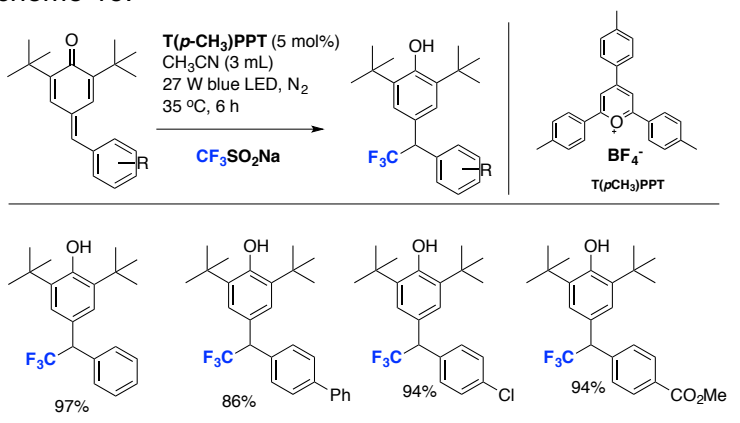

Scheme 15. Selected examples for the trifluoromethylation of $p$-quinone methides.

The authors postulated a reaction mechanism such as that shown in Scheme 16.

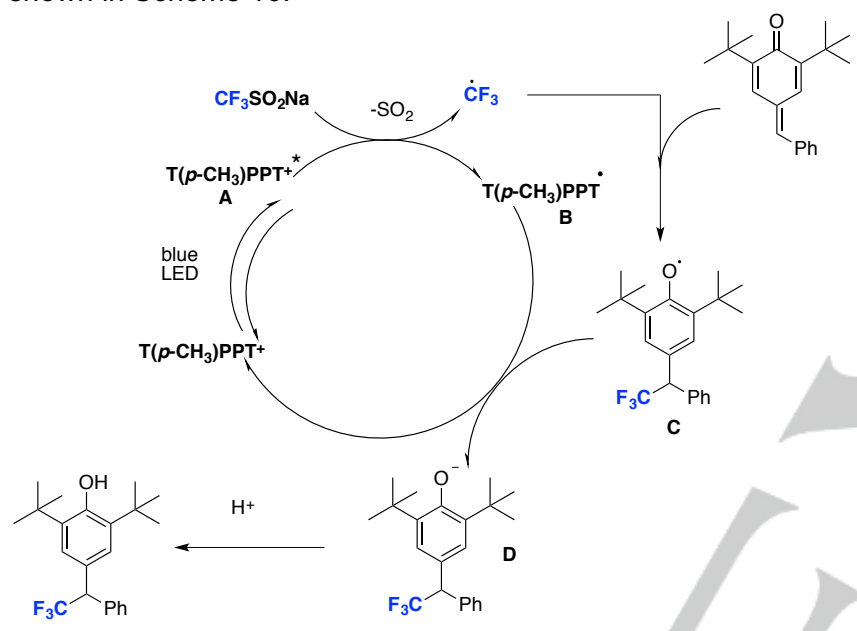

Scheme 16. Postulated reaction mechanism.

Firstly, the photocatalyst $\mathrm{T}\left(p-\mathrm{CH}_{3}\right) \mathrm{TTP}^{+}$is excited by means of irradiation with a blue LED, into an excited species $\mathbf{A}$ which is a highly oxidant form of the $\mathrm{PC}$, capable of accepting an electron from the Langlois reagent, to form $\mathrm{CF}_{3}$ radicals, and the reduced form of the $\mathrm{PC} \mathbf{B}$. These $\mathrm{CF}_{3}$ radicals add to the $p$-quinone methides to afford radical adduct $\mathbf{C}$ which is reduced to phenoxide anion $\mathbf{D}$. After protonation, anion $\mathbf{D}$ is converted to the phenol final product. It is noteworthy, that the $\mathrm{CF}_{3}$ radical adds to the benzylic carbon of $p$-quinone methides in a manner to generate a stable 2,6-ditertbutyl phenoxyl radical $\mathbf{C}$.

Moon, You, Cho, and colleagues [60] have recently accomplished the trifluoromethylation of alkenes employing tris(9anthryl)borane as photocatalyst. The authors [60] investigated the properties of the photocatalyst, and found them to be excellent for the $E T$ reduction of $\mathrm{CF}_{3}-\mathrm{I}\left(\mathrm{E}^{*}{ }_{\mathrm{ox}},-1.12 \mathrm{~V}\right.$ vs SCE; $\mathrm{E}^{*}$ ox $=\mathrm{E}_{\mathrm{ox}}-\mathrm{E}(\mathrm{S} 1)$, $E_{o x}(1.16 \mathrm{~V}$ vs SCE) and $E(\mathrm{~S} 1)(2.28 \mathrm{eV}))$. Selected examples of the scope of the transformation are depicted in Scheme 17.

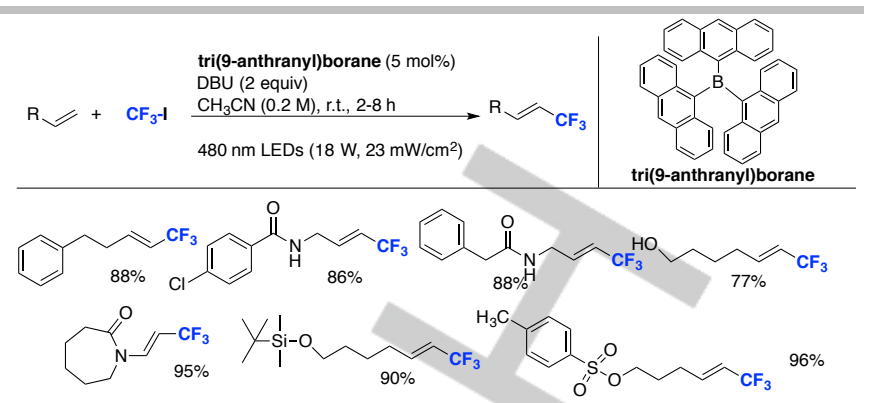

Scheme 17. Selected examples for the trifluoromethylation of olefins.

The authors [60] proposed a reaction mechanism such as that depicted in Scheme 18.

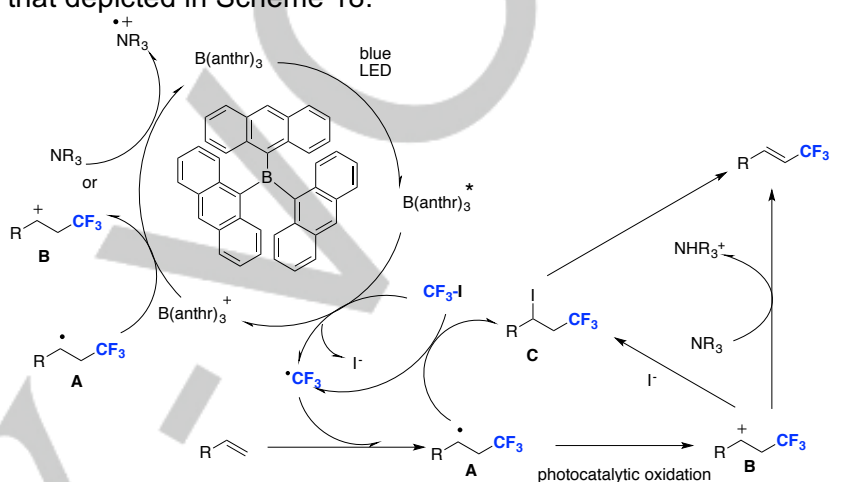

Scheme 18. Proposed reaction mechanism.

To start with, the tris(anthranyl)borane is excited by means of a blue LED, and is converted into a strong reductant species (i.e.: $\mathrm{B}(\text { anthr })_{3}{ }^{*}$ ), which reduces $\mathrm{CF}_{3}-\mathrm{I}$ to $\mathrm{CF}_{3}$ radicals and in turn the catalyst is oxidized to $\mathrm{B}(\mathrm{anthr})_{3}{ }^{+}$. The trifluoromethyl radicals add to the terminal olefinic carbon, to yield intermediate $A$ which upon electron transfer oxidation is converted to carbocation $\mathbf{B}$ by $\mathrm{B}$ (anthr) $)_{3}{ }^{+}$. Intermediate $\mathbf{B}$ can suffer nucleophilic attack by iodide anion to yield the ATRA product $\mathbf{C}$, or $\mathbf{B}$ can undergo basepromoted proton elimination to afford the trifluoromethylated olefin. Analogously, dehydrohalogenation of $\mathbf{C}$ can afford the $\mathrm{CF}_{3-}$ substituted olefin.

Yu, Zhang, Deng and colleagues [61] have recently reported the Eosin B-photocatalyzed trifluoromethylation of coumarins with the Togni reagent. A summary of the scope of the reaction is depicted in Scheme 19.

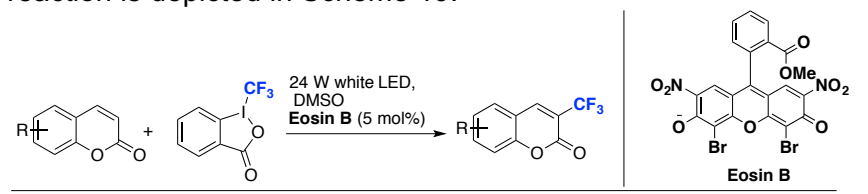

$$
\mathrm{F}_{70 \%}^{\mathrm{CF}_{3}}
$$

Scheme 19. Selected examples for trifluoromethylation of coumarins.

The proposed reaction mechanism is shown in Scheme 20. 
WILEY-VCH

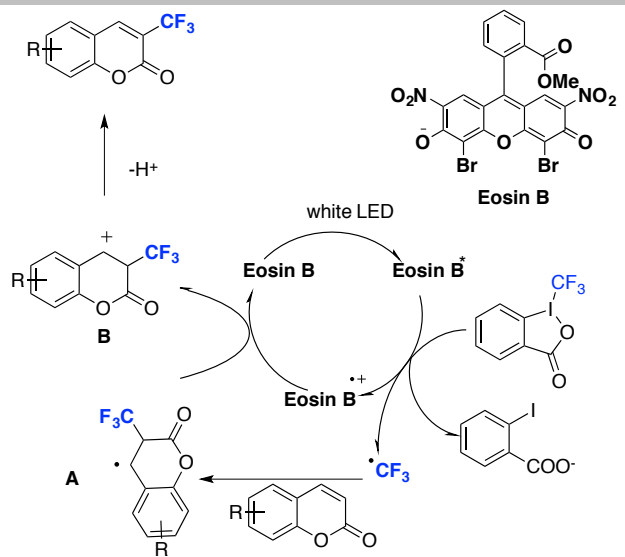

Scheme 20. Proposed reaction mechanism for the Eosin Bphotocatalyzed trifluoromethylation of coumarins.

The authors [61] show that upon visible light photoexcitation of Eosin $\mathrm{B}$, reduction of Togni reagent ensues, producing $\mathrm{CF}_{3}$ radicals that add to the coumarin enone system, to produce radical adduct $\mathbf{A}$, which by oxidation by the radical cation of Eosin B, affords benzylic cation B. Upon deprotonation, cation B gives the $\mathrm{CF}_{3}$-substituted coumarin derivative.

\section{1.-Multicomponent reactions. Addition of $\mathrm{CF}_{3}$ and $\mathrm{Y}$ groups onto carbon-carbon multiple bonds}

The photocatalyzed multicomponent trifluoromethylation reactions (PMCTRs) of alkenes have emerged as a powerful and ecofriendly methodology from the viewpoint of safety, simplicity, and efficiency. The photocatalytic trifluoromethylative difunctionalization of alkenes with the simultaneous introduction of both $\mathrm{CF}_{3}$ and $\mathrm{OH}(\mathrm{R}), \mathrm{NHR}$, and nucleophile groups have been summarized in review articles up to 2015.[57,55] In such processes, two bonds are formed with the concomitant incorporation of both the $\mathrm{CF}_{3}$ group and hydrogen,[42,46] oxygen,[62] nitrogen,[62e,63] halogen,[64] or carbon [62e,65] into the carbon-carbon multiple bond. Following are the most recent examples of newly developed strategies for PMCTRs.

\subsection{1.-Azido and amino trifluoromethylation of carbon- carbon multiple bonds}

Back in 2014, Dagousset, Magnier and Masson [66] had informed the photocatalyzed incorporation of the $\mathrm{CF}_{3}$ and azido groups onto alkenes. A wide range of substituted styrenes were treated under the optimized conditions, which consisted in $\left[\mathrm{Ru}(\mathrm{bpy})_{3}\left(\mathrm{PF}_{6}\right)_{2}\right]$ as the photocatalyst and Umemoto's reagent as the $\mathrm{CF}_{3}$ source. A general reaction scope of the reaction is depicted in Scheme 21.

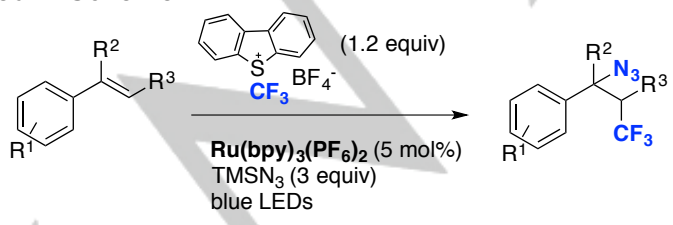

Scheme 21. Photocatalyzed azidotrifluoromethylation of alkenes.

More recently, Levitre, Magnier, Masson and colleagues [67] reported a photocatalyzed multi-component reaction involving an alkene, a carbonyl compound, $\mathrm{TMSN}_{3}$,
$\left[\mathrm{Ru}(\mathrm{bpy})_{3}\left(\mathrm{PF}_{6}\right)_{2}\right]$ as the photocatalyst, in the presence of Umemoto's reagent. Under these conditions, a wide range of terminal and internal alkenes, carbonyl compounds, $\mathrm{TMSN}_{3}$, and the trifluoromethyl source give rise to highly complex molecules in a single operation affording azidoalkoxytrifluoromethylation products. The scope of the transformation is represented in Scheme 22.

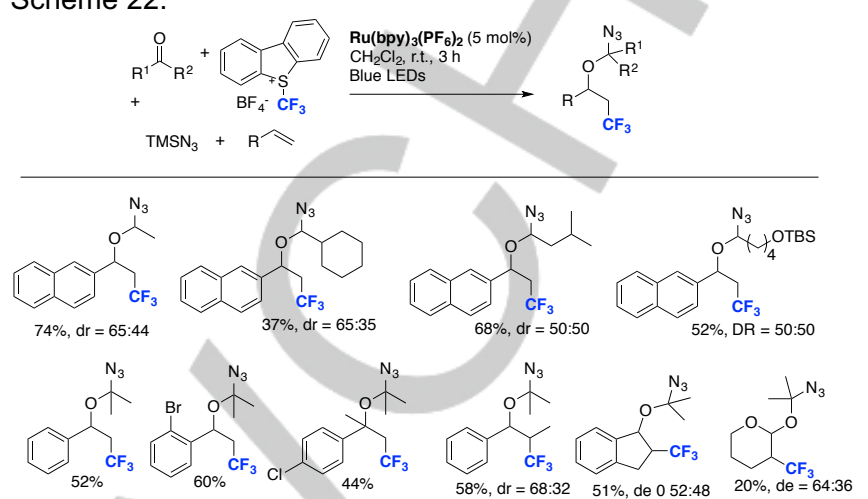

Scheme 22. Selected examples of the four-component photoredoxcatalyzed reaction using $\left[\mathrm{Ru}(\mathrm{bpy})_{3}\left(\mathrm{PF}_{6}\right)_{2}\right]$ as the photocatalyst, in the presence of Umemoto's reagent, a wide range of terminal and internal alkenes, a carbonyl compound, and $\mathrm{TMSN}_{3}$.

The authors [67] proposed a mechanism such as that illustrated in Scheme 23a based on several control experiments.

$$
\mathrm{R}^{4}{ }_{\mathrm{R}^{5}}^{\mathrm{O}}+\mathrm{TMSN}_{3} \longleftrightarrow \mathrm{R}^{4} \mathrm{X}_{\mathrm{R}^{5}}^{\mathrm{N}_{3}}
$$
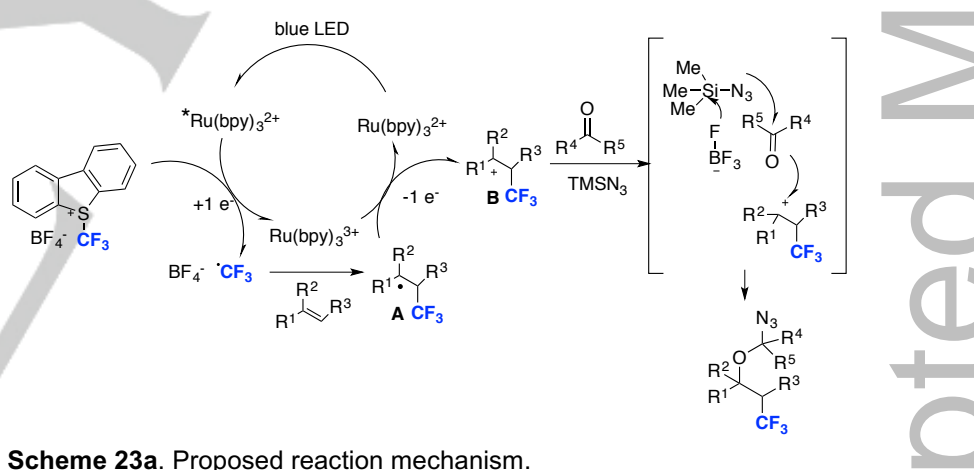

Visible light excitation of $\mathrm{Ru}(\mathrm{bpy}) 3^{2+}$ enables the $\mathrm{ET}$ reduction of the Umemoto reagent, to generate $\cdot \mathrm{CF}_{3}$. Ulterior addition of electrophilic $\cdot \mathrm{CF}_{3}$ radical to alkene leads to the radical species $\mathbf{A}$, which can be further oxidized into cation $\mathbf{B}$ by ET from the upper oxidation state of the photocatalyst (i.e.: $\operatorname{Ru}(\mathrm{bpy}) 3^{3+}$ ). Then, the corresponding cation $\mathbf{B}$ can act as an electrophilic species assisting the nucleophilic attack of $\mathrm{TMSN}_{3}$ to carbonyl compound with the tetrafluoroborate counter-anion acting as the source of fluoride ion.

\subsection{2.-Addition of $\mathrm{CF}_{3}$ and $\mathrm{SO}_{2} \mathrm{Cl}$ groups to alkenes}

Oh, Jung, Han and colleagues had shown that $\left[\mathrm{Ru}(\mathrm{bpy})_{3}\right] \mathrm{Cl}_{2}$ can photocatalyze the incorporation of both $\mathrm{CF}_{3}$ and $\mathrm{Cl}$ moieties onto alkenes employing triflic chloride as the source of $\mathrm{Cl}$ and $\mathrm{CF}_{3 .[68]}$ A succinct scope of the transformation is depicted in Scheme 23b. 
WILEY-VCH

visible light

Scheme 23b. Scope of the photocatalyzed chloro-trifluoromethylation of alkenes.

On the other hand, Bagal, Reiser, and colleagues [69] reported the photocatalyzed trifluoromethylchlorosulfonylation (incorporation of the chlorosulfonyl and trifluoromethyl groups onto the carbon-carbon double bond) of inactivated alkenes employing triflyl chloride and $\left[\mathrm{Cu}(\mathrm{dap})_{2}\right] \mathrm{Cl}[70]$ as photocatalyst suggesting a mechanism of inner sphere electron transfer. The substrate scope is represented in Scheme 24.

$$
\mathrm{R} \curvearrowright \stackrel{\substack{\mathrm{CF}_{3} \mathrm{SO}_{2} \mathrm{Cl}(2 \mathrm{mmol}) \\ \mathrm{K}_{2} \mathrm{HPO}_{4}(2 \mathrm{mmol}) \\ \mathrm{Cu}(\mathrm{dap})_{2} \mathrm{Cl}(1 \mathrm{~mol} \%) \\ \mathrm{MeCN}, \mathrm{LED}}}{\longrightarrow}
$$

$1 \underset{\mathrm{SO}_{2} \mathrm{Cl}}{\mathrm{CF}_{3}} \overbrace{\mathrm{SO}_{2} \mathrm{Cl}}^{\mathrm{CF}_{3}} \overbrace{\mathrm{MeO}}^{\mathrm{SO}_{2} \mathrm{Cl}_{3}} \underset{\mathrm{SO}_{2} \mathrm{Cl}_{3}}{\mathrm{CF}_{3}}$

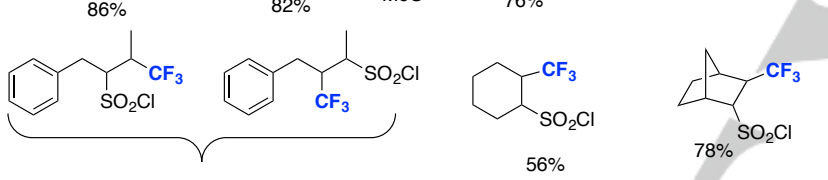

Scheme 24. Selected examples for the trifluoromethylchlorosulfonylation of alkenes.

The difference of $\left[\mathrm{Cu}(\mathrm{dap})_{2}\right] \mathrm{Cl}$ to $\mathrm{Ru}-$, Ir-, or Eosin $\mathrm{Y}$ photocatalysts (which in the presence of triflyl chloride effect addition of both $\mathrm{Cl}$ and $\mathrm{CF}_{3}$ groups onto alkenes) suggests the relevant role of copper in the whole process. Thus, $\mathrm{Cu}$ presumably coordinates $\mathrm{SO}_{2} \mathrm{Cl},[71,72]$ thus retaining it within the reactive intermediates. The authors [69] ruled out a radical chain mechanism (a quantum yield of 0.12 was determined for this process). With the evidence, the authors [69] proposed a reaction mechanism where photoexcited $\left[\mathrm{Cu}-(\mathrm{dap})_{2}\right] \mathrm{Cl}^{*}$ reduces triflyl chloride by an electron transfer, with concomitant oxidation of $\mathrm{Cu}^{\prime}$ to $\mathrm{Cu}^{\text {ll }}$ giving rise to $\mathbf{A}$ (Scheme 25). Addition of the $\mathrm{CF}_{3}$ radical to the double bond is followed by the binding with copper ligand; on account of the instability of free $\mathrm{SO}_{2} \mathrm{Cl}-$, this rapidly decomposes to $\mathrm{SO}_{2}$ and $\mathrm{Cl}-$. Nevertheless, the binding of $\mathrm{SO}_{2} \mathrm{Cl}-$ to copper appears to be weak, which might explain the observation of trifluoromethylchlorination with alkenes that contain donor atoms (Scheme 25). It is believed that $\left[\mathrm{Cu}(\mathrm{dap})_{2}\right] \mathrm{Cl}$ plays more than one role, i.e., acting both as an electron transfer reagent and as coordinating the reactants in the bond forming processes as well.

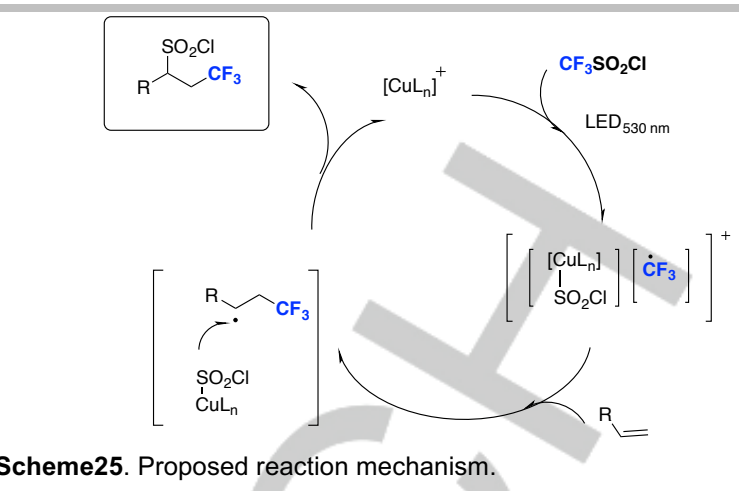

\subsection{3.-Addition of $\mathrm{CF}_{3}$ and OCOR groups onto carbon-carbon multiple bonds}

Zhou, Li, and She [73] have recently reported a white LEDstriggered-photocatalytic incorporation of both acyl and $\mathrm{CF}_{3}$ groups onto alkenes employing a new Umemoto's reagent as source of $\mathrm{CF}_{3}$ radicals, $\mathrm{Ru}(\mathrm{bpy})_{3}\left(\mathrm{PF}_{6}\right)_{2}$ as photocatalyst, in DMF or DMA as solvents under. The scope of the transformation is illustrated in Scheme 26

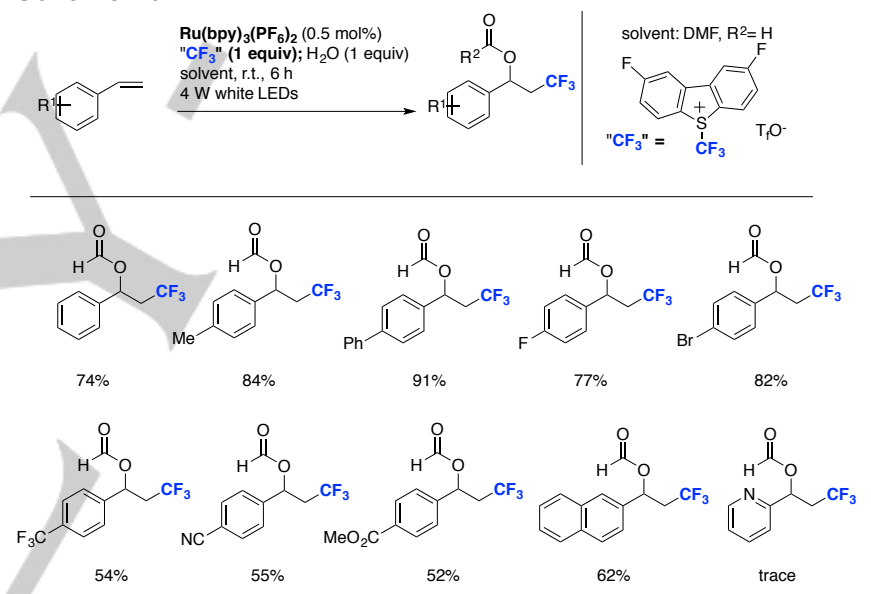

Scheme 26. Selected examples for the acyloxy-trifluoromethylation of alkenes.

The authors [73] attempted several mechanistic probe experiments in order to elucidate the reaction pathway. Adding 2 equiv. of TEMPO, the acyloxy-trifluoromethylation of a vinylbenzene does not take place, indicating the involvement of a radical pathway. Replacing $\mathrm{H}_{2} \mathrm{O}$ with $\mathrm{D}_{2} \mathrm{O}$, no deuterated product was encountered. However, when using DMF- $d_{7}$ as solvent, a $99.5 \%$ incorporation of deuterium was found. This demonstrates that the $\mathrm{H}$ atom of the formyloxy group arises from the dimethyl formamide solvent, rather than $\mathrm{H}_{2} \mathrm{O}$. When $\mathrm{H}_{2}{ }^{18} \mathrm{O}$ was employed, the corresponding product with $\mathrm{O}^{18}$-labeled was isolated in $81 \%$ yield. These results showed that the oxygen atom of the $\mathrm{CHO}$ group comes from $\mathrm{H}_{2} \mathrm{O}$, and the other oxygen atom originated from DMF. Based on the above and other photocatalytic experiments, the authors [73] proposed a reaction mechanism as illustrated in Scheme 27. 
WILEY-VCH

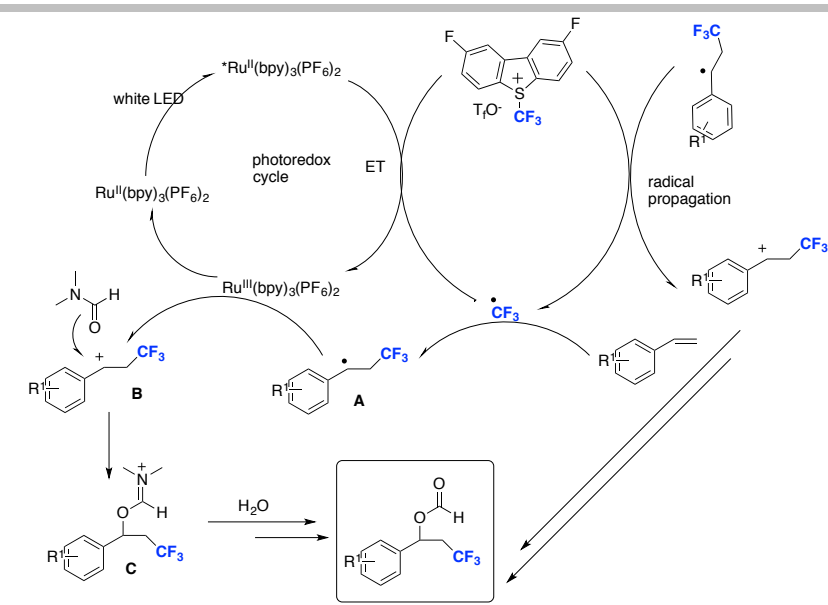

Scheme 27. Proposed reaction mechanism.

In the proposed mechanism [73], the excited $\mathrm{Ru}(\mathrm{II})$ photocatalyst reduces the Umemoto's reagent to $\mathrm{CF}_{3}$ radicals and generates a very oxidant state of the photocatalyst (i.e.: $\mathrm{Ru}(\mathrm{III})$ ), which add to the terminal olefinic carbon of the vinyl arene to form intermediate $\mathbf{A}$. Intermediate $\mathbf{A}$ is oxidized to benzylic cation $B$ by the upper oxidation state of the photocatalyst $(R u(I I I))$. Nucleophilic attack by the DMF solvent affords intermediate C which is promptly hydrolyzed to final product (Scheme 27).

\subsection{4.-Photocatalytic Incorporation of Pyridyl and CF3 groups onto Alkenes}

The strategy for the simultaneous installation of both trifluoromethyl and pyridyl groups into various organic molecules continues to be challenging owing to the potential competition between reactive species.

$\mathrm{He}$, Hong, and colleagues [74] achieved the incorporation of both pyridyl and $\mathrm{CF}_{3}$ groups onto inactivated alkenes by visible-lightinduced-transition metal-free photoredox catalysis employing $\mathrm{CF}_{3} \mathrm{SO}_{2} \mathrm{Na}$ and a pyridinium salt in the presence of Eosin $\mathrm{Y}$ as a photoredox catalyst. The substrate scope is depicted in Scheme 28.

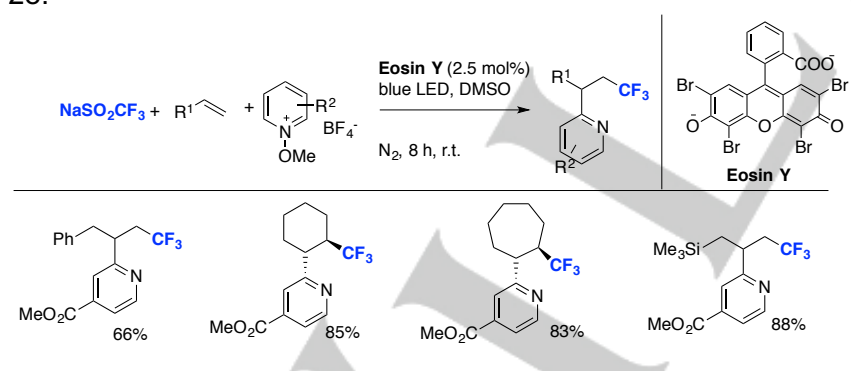

Scheme 28. Selected examples of the trifluoromethylative pyridylation of inactivated alkenes by visible-light-induced photoredox catalysis employing $\mathrm{CF}_{3} \mathrm{SO}_{2} \mathrm{Na}$ and a pyridinium salt in the presence of Eosin $\mathrm{Y}$ as a photoredox.

The authors [74] investigated the reaction mechanism, and proposed a catalytic cycle such as that shown in Scheme 29.

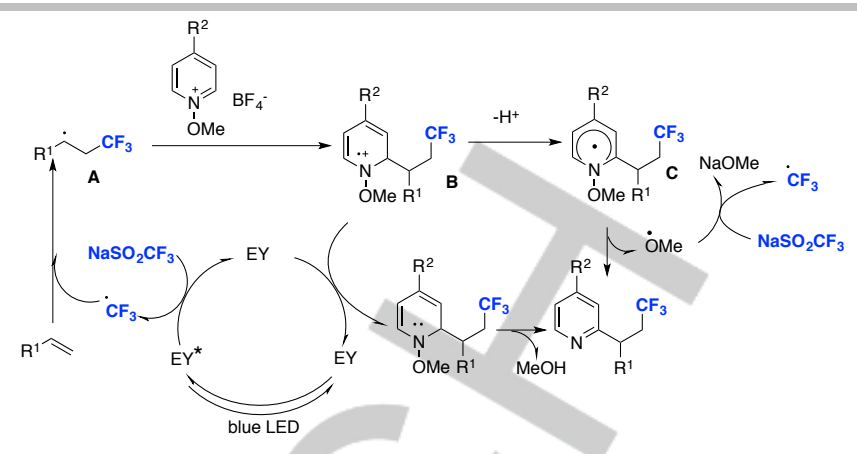

Scheme 29. Proposed reaction mechanism.

In the mechanism proposed, the visible-light excited Eosin $\mathrm{Y}$ oxidizes the Langlois reagent to $\mathrm{CF}_{3}$ radicals, which add to the terminal carbon position of the olefin to produce adduct $\mathbf{A}$. The adduct generated attacks homolytically the pyridinium tetrafluoroborate salt, forming adduct B. Upon deprotonation, radical cation intermediate $\mathbf{B}$ yields the radical $\mathbf{C}$, which loses a methoxyl radical to re-aromatize.

\subsection{5.-Oxidative addition of Both $\mathrm{CF}_{3}$ and $\mathrm{H}_{2} \mathrm{O}$ to alkynes}

The most common routes to $\alpha-\mathrm{CF}_{3}$ ketones have been reviewed and involve the use of enolates or enol ethers as substrates.[75,76] However, other indirect routes have been informed.[77] For $\beta-\mathrm{CF}_{3}$ ketones, the photocatalyzed trifluoromethylation of propargylic alcohols is a standardized procedure.[78]

\section{2.-Trifluoromethylation of Carbon-Carbon Multiple Bonds with Ulterior Cyclization}

The photocatalytic radical-mediated addition/cyclization across a carbon-carbon multiple bond provides an attractive platform for construction of various biologically important and functionalized (hetero)cycles. A plethora of reactions have been informed under this fashion where a large variety of allylic alcohols and amines,[79] $\mathrm{N}$-arylacrylamides,[80] and alkenoic acids [81] were easily transformed into the corresponding $\mathrm{CF}_{3}$ substituted three-, five, six-, and seven-membered oxygen and/or nitrogen heterocycles with good yields and selectivities. Also photocatalytic radical trifluoromethylation/cyclization cascade reactions of $\mathrm{N}$-allylamines [82], cycloalkanols substituted styrenes [83] have been informed by the group of Glorius and Chen. $\beta$-aryl$\beta, \gamma$-unsaturated hydrazones and oximes have been used as substrates for the visible light induced photoredox-catalyzed radical trifluoromethylation/cyclization cascade.[84] Also, the synthesis of a variety of $\mathrm{CF}_{3}$-containing dihydroquinolin-2(1H)ones and 1-azaspiro[4.5]decanes has been achieved through the visible-light induced trifluoromethylation of $N$-arylcinnamamides with Togni's reagent in 2015 by Gao, Xia and colleagues.[85] Zhou and Wang [86] have accomplished the fac-Ir(ppy) 3 photoredox-catalyzed trifluoromethylation of $\mathrm{N}$-methacryloyl benzamides with trifluoromethyl sulfone towards the synthesis of trifluoromethylated isoquinoline-1,3(2H,4H)-diones via a radical process. The scope of the transformation is illustrated in Scheme 30 . 
WILEY-VCH

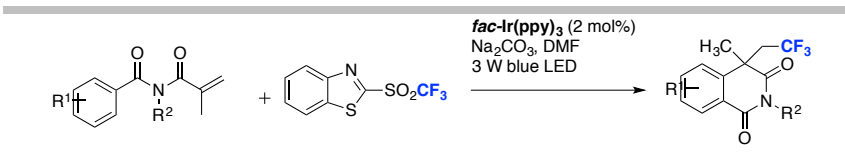

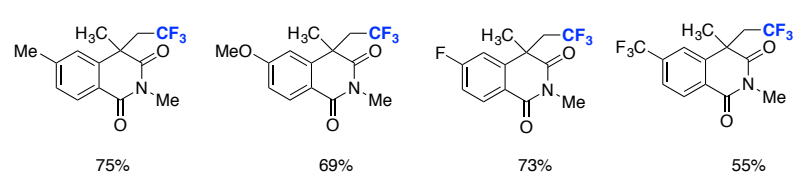

$$
\begin{aligned}
& 69 \% \\
& 73 \%
\end{aligned}
$$

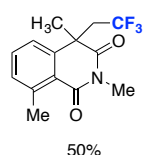

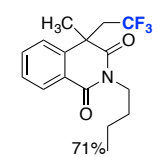

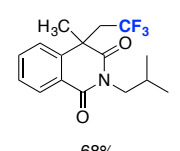

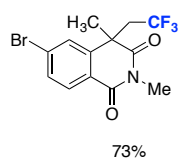

Scheme 30. Selected examples of fac-Ir(ppy) ${ }_{3}$-photoredox-catalyzed trifluoromethylation of $\mathrm{N}$-methacryloyl benzamides with trifluoromethyl sulfone.

The authors [86] realized a series of probe experiments with the aim to investigate the reaction mechanism. When TEMPO was added into the system, no desired product was observed, indicating the presence of radicals. The mechanistic proposal is depicted in Scheme 31 below.

Upon visible light excitation, $\left[\right.$ fac- $\left.\operatorname{Ir}(\mathrm{III})(\mathrm{ppy})_{3}{ }^{*}\right]$ is formed. Then, the interaction of fluorinated sulfone with the excited state $\left[\right.$ fac- $\left.-\mathrm{Ir}(\mathrm{III})(\mathrm{ppy})_{3}{ }^{*}\right]$ generates the $\mathrm{CF}_{3}$ radical and the strong oxidant $\left.[\text { fac-Ir(IV)(ppy) })_{3}\right]$. Next, the reaction of $\mathrm{CF}_{3}$ radical with methacryloyl benzamide yields a radical intermediate $\mathbf{B}$, which undergoes intramolecular cyclization on the aromatic ring, generating intermediate $\mathbf{C}$. The intermediate $\mathbf{C}$ is then oxidized by $\left[\text { fac- } \operatorname{Ir}(\mathrm{IV})(\mathrm{ppy})_{3}\right]^{+}$to form the Wheland intermediate $\mathbf{D}$ with the concurrent regeneration of $\left[\mathrm{fac}-\mathrm{Ir}(\mathrm{III})(\mathrm{ppy})_{3}\right]$. Finally, baseassisted deprotonation affords the desired product (Scheme 31 ).

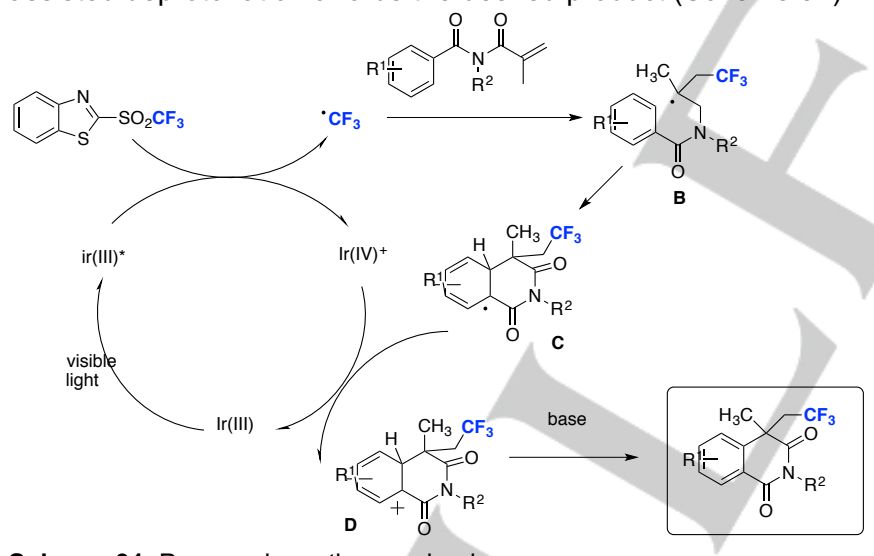

Scheme 31. Proposed reaction mechanism.

1,7-Enynes have been used as substrates for the simultaneous photocatalyzed incorporation of halogen and $\mathrm{CF}_{3}$ groups by Yuan, Li, and Guo.[87]. This photocatalytic protocol provides a strategy leading to $\mathrm{CF}_{3}$ - and halogen-containing 3,4dihydroquinolin-2 $(1 H)$-ones from a wide range of 1,7-enynes through two different radical pathways. One pathway involves the use of Langlois reagent $\mathrm{CF}_{3} \mathrm{SO}_{2} \mathrm{Na}$ as a source of $\mathrm{CF}_{3}$ radicals and mesityl acridinium as photocatalyst, and another the employment of $\mathrm{fac}-\operatorname{Ir}(\mathrm{ppy})_{3}$ as photocatalyst and triflyl chloride $\mathrm{CF}_{3} \mathrm{SO}_{2} \mathrm{Cl}$ as source of $\mathrm{CF}_{3}$ radicals.

In $2018 \mathrm{Bu}$, Cai, and collaborators [88a] have accomplished the photocatalyzed trifluoromethylation of alkynes with subsequent cyclization of the aryl alkynoates towards the synthesis of coumarins with trifluoromethyl groups. The photocatalyst employed was $\operatorname{Ir}(\mathrm{ppy})_{3}, \mathrm{CF}_{3} \mathrm{SO}_{2} \mathrm{Cl}$ as source of $\mathrm{CF}_{3}$ radicals, in $\mathrm{MeCN}$ as solvent, with $\mathrm{K}_{2} \mathrm{CO}_{3}$ as base, irradiating with blue LEDs. Selected examples are shown in Scheme 32.

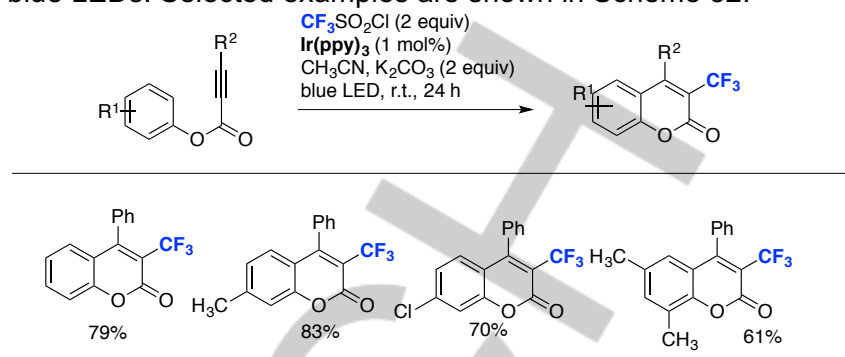

Scheme 32. Substrate scope of the cyclization of aryl alkynoates with $\mathrm{CF}_{3} \mathrm{SO}_{2} \mathrm{Cl}$.

In this reaction, the photocatalyst acts in an oxidative quenching cycle. The $\mathrm{Ir}(\mathrm{III})$ photocatalyst transfers an electron to $\mathrm{CF}_{3} \mathrm{SO}_{2} \mathrm{Cl}$, to generate $\mathrm{CF}_{3}$ radicals together with chloride anions and $\mathrm{SO}_{2}$. The $\mathrm{CF}_{3}$ radical adds to the $s p$ carbon next to the CO-O functionality, generating a $\mathrm{CF}_{3}$-substituted vinyl radical that achieves a homolytic aromatic substitution, forming a radical intermediate which is oxidized by $\operatorname{Ir}(\mathrm{IV})$, re-generating the active $\mathrm{PC}$ and a Wheland intermediate, which undergoes deprotonation by the base affording the final product.

Guo and collaborators [88b] developed two methodologies for the photoredox-catalyzed halo-trifluoromethylation of 1,7 enynes towards the synthesis of 3,4-dihydroquinolin-2(1H)ones. Methodology 1 , useful for the synthesis of $\mathrm{Cl}$ or $\mathrm{Br}$-containing $(E)$ 3,4-dihydroquinolin-2(1H)ones, employs $\mathrm{CF}_{3} \mathrm{SO}_{2} \mathrm{Na}$ as the ${ }^{-} \mathrm{CF}_{3}$ radical source, $\mathrm{N}$-chlorophthalimide or $\mathrm{N}$-bromophthalimide as the $\mathrm{Cl}$ or $\mathrm{Br}$ atom source respectively, $\mathrm{N}$-methyl-9-mesityl acridinium perchlorate (Mes-Acr ${ }^{+}$) as photocatalyst in acetonitrile as solvent under blue LEDs irradiation; selected examples of the substrate scope are shown in Scheme 33. Methodology 2, only useful for the synthesis of $\mathrm{Cl}$-containing $(E)$-3,4-dihydroquinolin$2(1 H)$ ones, employs trifluoromethanesulfonyl chloride $\left(\mathrm{CF}_{3} \mathrm{SO}_{2} \mathrm{Cl}\right)$, as both ${ }^{\circ} \mathrm{CF}_{3}$ radical and $\mathrm{Cl}$ atom sources, fac- $\mathrm{Ir}(\mathrm{ppy})_{3}$ as photocatalyst and acetonitrile as solvent under blue LEDs irradiation; this methodology also exhibited a wide substrate scope (Scheme 34). The authors [88b] accomplished several control experiments and suggest the radical mechanism depicted in Scheme 35. Initially, blue light excites the Mes-Acr ${ }^{+}$ photocatalyst affording Mes-Acr ${ }^{+*}$ which oxidizes $\mathrm{CF}_{3} \mathrm{SO}_{2} \mathrm{Na}$ yielding ${ }^{\circ} \mathrm{CF}_{3}$ radicals, $\mathrm{SO}_{2}$ and acridine radical. The ${ }^{\circ} \mathrm{CF}_{3}$ radical is captured by the $\mathrm{C}-\mathrm{C}$ double bond of the 1,7-enyne furnishing a quaternary radical adduct that undergoes 6 -exo-dig cyclization to form radical intermediate $\mathbf{A}$. Afterwards, radical $\mathbf{A}$ abstracts a $\mathrm{Cl}$ atom from $\mathrm{N}$-chlorophthalimide affording the desired reaction product. The mechanism proposed for method 2 is comparable to method 1 but involving an $\mathrm{Ir}^{\mathrm{III} /} / \mathrm{Ir}^{\mathrm{IV}}$ photoredox cycle for generating ${ }^{\circ} \mathrm{CF}_{3}$ radicals and $\mathrm{Cl}^{-}$. The ${ }^{\circ} \mathrm{CF}_{3}$ radical upon addition to the $\mathrm{C}-\mathrm{C}$ double bond of the 1,7-enyne, finally forms the cyclized radical adduct $\mathbf{A}$ which can be oxidized by reaction with $\mathrm{CF}_{3} \mathrm{SO}_{2} \mathrm{Cl}$ or $\mathrm{Ir}^{\mathrm{IV}}$, generating carbocation $\mathbf{B}$ that is subsequently attacked by $\mathrm{Cl}^{-}$ generating the reaction product. 
WILEY-VCH
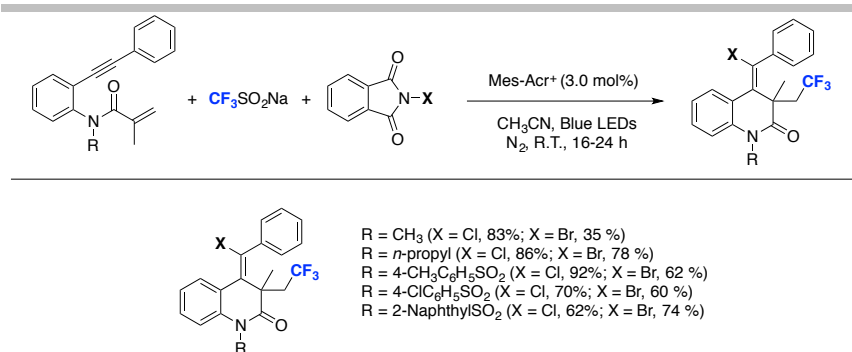

Scheme 33. Selected examples for the synthesis of $\mathrm{Cl}$ or $\mathrm{Br}$-containing (E)-3,4-dihydroquinolin-2(1H)ones employing $\mathrm{CF}_{3} \mathrm{SO}_{2} \mathrm{Na}$ as the ${ }^{\circ} \mathrm{CF}_{3}$ radical source and $\mathrm{N}$-chlorophthalimide or $\mathrm{N}$-bromophthalimide as the $\mathrm{Cl}$ or $\mathrm{Br}$ source respectively.

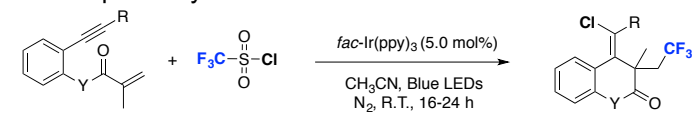$$
\text { (c) }
$$

Scheme 34. Selected examples for the synthesis of Cl-containing $(E)-3,4-$ dihydroquinolin-2(1H)ones employing $\mathrm{CF}_{3} \mathrm{SO}_{2} \mathrm{Cl}$ as ${ }^{\circ} \mathrm{CF}_{3}$ radical and $\mathrm{Cl}$ atom source.

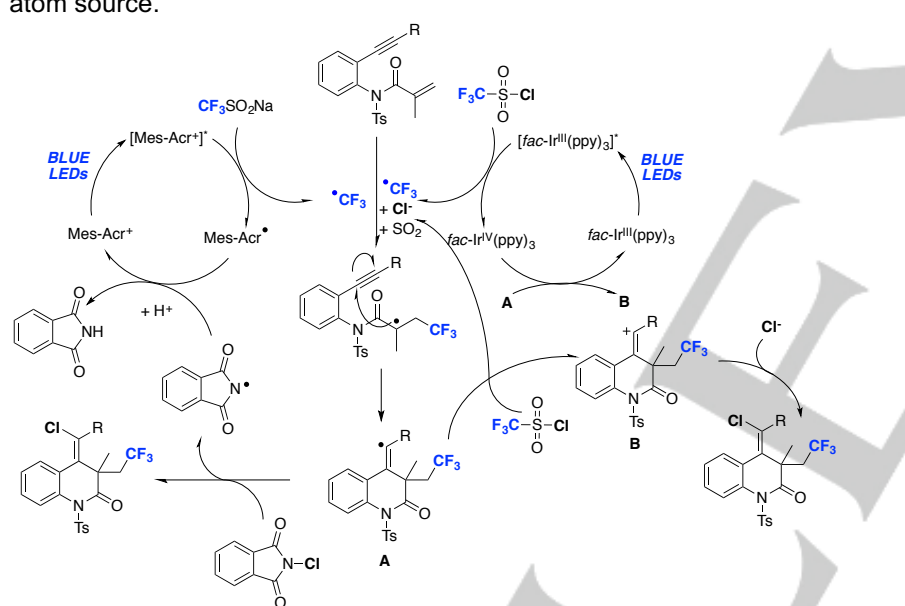

Scheme 35. Proposed mechanism for the photoredox-catalyzed chlorotrifluoromethylation of 1,7-enynes for the synthesis of $(E)-3,4$ dihydroquinolin-2(1H)ones using methodologies 1 and 2.[88b]

\section{3.-Photocatalytic Trifluoromethylation of Carbon-carbon Multiple Bonds and Ulterior Rearrangement}

The visible-light-photocatalytic carbotrifluoromethylation of allylic alcohols with $\mathrm{NaSO}_{2} \mathrm{CF}_{3}$ through 1,2-migration of an aryl group has been investigated by Cai and colleagues [89], affording $\beta$-trifluoromethyl- $\alpha$-substituted carbonyl compounds under mild reaction conditions. The $\mathrm{CF}_{3}$ radical is generated from oxidation of $\mathrm{NaSO}_{2} \mathrm{CF}_{3}$ by visible light-excited 1,2,3,5- tetrakis(carbazol-9yl)-4,6-dicyanobenzene (4CzIPN) photocatalyst [ $\mathrm{E}_{\mathrm{red}}$ $1 / 2$ ( ${ }^{*} \mathrm{PC} / \mathrm{PC}-$ ) $\left.=+1.35 \mathrm{~V}\right]$. Subsequent $\mathrm{CF}_{3}$ radical addition to the terminal olefinic carbon of the allylic alcohol and 1,2-aryl migration would yield $\beta$ - trifluoromethyl- $\alpha$-aryl ketones. The scope of the transformation is briefly depicted in Scheme 36 .
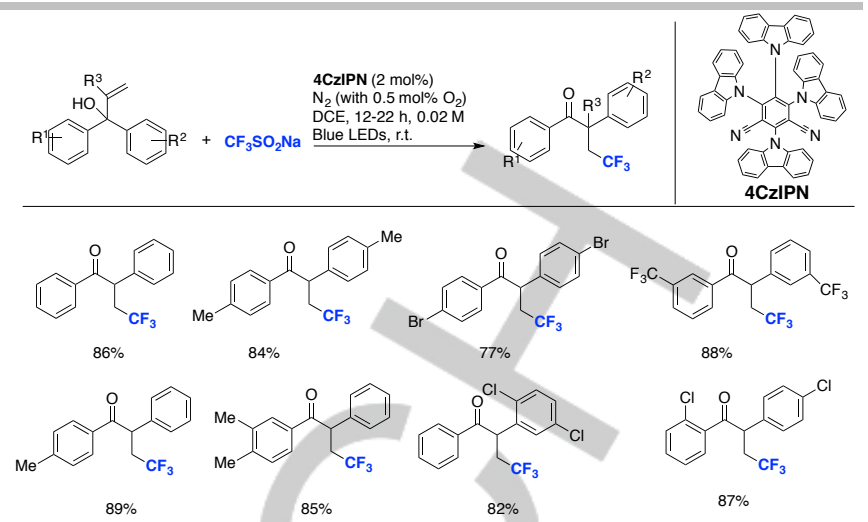

Scheme 36. Scope of the trifluoromethylation of allylic alcohols.

In order to elucidate the reaction mechanism, control experiments were performed. When TEMPO was added into the reaction mixture as a radical scavenger, complete inhibition of the reaction was observed. These results supported that the reaction should follow a radical pathway. Interestingly, when the reaction was performed in the presence of an $\mathrm{O}_{2}$ atmosphere under otherwise identical reaction conditions, benzophenone was furnished in excellent isolated yield, but no migratory product was observed. With the above control experiments and others, the authors [89] proposed a reaction mechanism such as that depicted in Scheme 37.

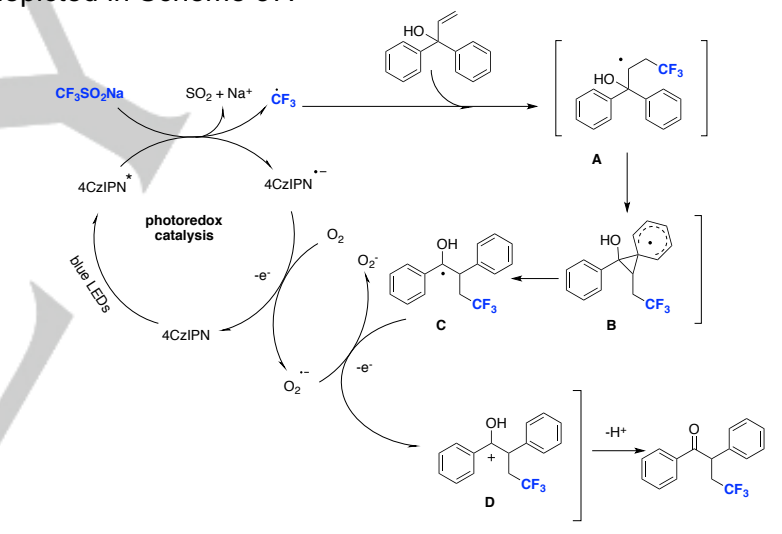

Scheme 37. Proposed reaction mechanism.

In the proposed mechanism (Scheme 37), the authors [89] considered that the photoexcited catalyst $4 \mathrm{CzIPN}$ (see Figure 3 for photocatalyst structure) oxidizes the $\mathrm{CF}_{3} \mathrm{SO}_{2} \mathrm{Na}$ to $\mathrm{CF}_{3}$ radicals, generating the radical anion of the photocatalyst. In turn, the $\mathrm{CF}_{3}$ radicals, add to the terminal olefinic carbon of the allylic alcohol, producing intermediate $\mathbf{A}$ which by 1,2-aryl migration via spiro[2,5]octadienyl affords radical intermediate $\mathbf{B}$. This radical intermediate $\mathbf{B}$ evolves to intermediate $\mathbf{C}$ by bond breaking, which is oxidized by the superoxide anion to benzylic intermediate $\mathbf{D}$. Upon proton loss, intermediate $\mathbf{D}$ affords the final product.

Chandu, Sureshkumar and colleagues [90] have accomplished the synthesis of allylic compounds with the $\mathrm{CF}_{3}$ group with high yield and $E / Z$ selectivity using visible light photoredox catalysis and sodium triflinate as a trifluoromethylation source, starting from vinylcyclopropanes. The authors employed $\left[\mathrm{Ir}\left\{\mathrm{dFCF}_{3} \text { ppy }\right\}_{2}\right.$ (dtbbpy)]PF$F_{6}$ as photocatalyst in DME as solvent with water irradiating with blue LEDs. Selected examples of the reaction are illustrated in Scheme 38. 
WILEY-VCH

REVIEW

等

(1)

$\underbrace{C F_{3}}_{85 \%}$

Scheme 38. Selected examples for the synthesis of allylic trifluoromethylated.

In the mechanism proposed by the authors, the Ir photocatalysts acts in a reductive quenching cycle. The same authors [91] have developed, in another report, the metal-free pyrilium salt $\mathrm{T}\left(p-\mathrm{CH}_{3}\right) \mathrm{PPT}$ (see Figure 3 for photocatalyst structure)-photocatalyzed strategy for the trifluoromethylation of vinylcyclopropanes.

Singh and collaborators [92] developed a photoredox metalfree methodology towards the synthesis of allylictrifluoromethylated alkenes using $\mathrm{CF}_{3} \mathrm{SO}_{2} \mathrm{Na}$ (Langlois reagent) as ${ }^{\circ} \mathrm{CF}_{3}$ radical source, eosin $\mathrm{Y}$ as photocatalyst, Baylis-Hillman acetates (BH-OAc) as substrates, DMSO as solvent, without inert atmosphere and under high power green LEDs irradiation. The reaction was successful when employing different $\mathrm{BH}-\mathrm{OAc}$ with different substituents on the aromatic ring and a variety of electron withdrawing groups (EWG) on the olefinic carbon, affording the reaction products in reasonably high yields (Scheme 39 ). The authors [92] propose a mechanism initiated upon excitation of $E Y$ by green light, followed by electron transfer from $\mathrm{CF}_{3} \mathrm{SO}_{2} \mathrm{Na}$ to $\mathrm{EY}^{*}$ to yield ${ }^{\circ} \mathrm{CF}_{3}$ radicals, $\mathrm{SO}_{2}$ and $\mathrm{EY}^{*}$. The reaction between ${ }^{\circ} \mathrm{CF}_{3}$ radicals and $\mathrm{BH}-\mathrm{OAc}$ affords radical adduct $\mathrm{A}$ that is reduced by reaction with $\mathrm{EY}^{--}$rendering carbanion $\mathbf{B}$, stabilized by the presence of the EWG, and regenerating the photocatalyst EY. Finally, carbocation B incurs deacetoxylation to afford the reaction product (Scheme 40).

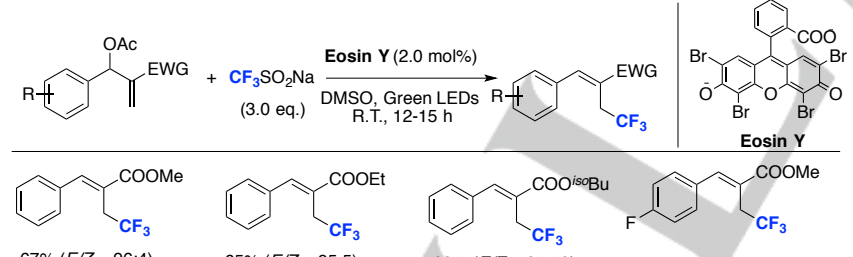
$65 \%(E / Z=95: 5)$

$63 \%(E / Z=81: 19)$

$63 \%(E / Z=95: 5)$

Scheme 39. Selected examples for the scope of the synthesis of allylictrifluoromethylated alkenes by g-trifluoromethylation of Baylis-Hillman acetates.

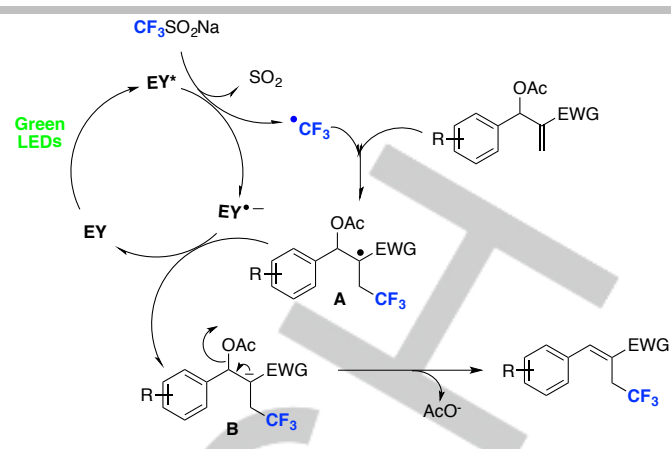

Scheme 40. Proposed reaction mechanism for the of allylictrifluoromethylated alkenes using $\mathrm{CF}_{3} \mathrm{SO}_{2} \mathrm{Na}$ (Langlois reagent) as ${ }^{\circ} \mathrm{CF} 3$ radical source, eosin $Y$ as photocatalyst, Baylis-Hillman acetates as substrates, under high power green LEDs irradiation.

\section{4.-Conclusions and Perspectives}

Trifluoromethyl group incorporation into organic substrates by means of visible-light-photocatalysis is an area of constant evolution. Much work has been done on trifluoromethylation strategies of (hetero)aromatic substrates involving Ru-, and Irbased photocatalysts, employing triflic chloride, Langlois reagent, Togni reagent and $\mathrm{CF}_{3}-\mathrm{I}$ as sources of $\mathrm{CF}_{3}$ radicals. Also, using the same sources of $\mathrm{CF}_{3}$ radicals, organic-dye-photocatalyzed strategies have been developed for substitution of (hetero)aromatic substrates with $\mathrm{CF}_{3}$ moieties. Other organic photocatalysts, such as quinone-, anthraquinone- and benzophenone- derivatives have been employed as sensitizers and activated by white light or near UV-light for trifluoromethylation reactions of (hetero)aromatics. However, the use of non-metal all-organic-semiconductors that can be activated by visible light are starting to play a promising role for the incorporation of $\mathrm{CF}_{3}$ moieties into (hetero)aromatic substrates, as exemplified by the employment of graphine oxide (GO) and mesoporous graphitic carbon nitride $(m p g C N)$. This latter (i.e.: $m p g(C N)$, resulted particularly relevant in synthetic transformations, as it allows biofunctionalization of heteroarenes with two different $\mathrm{C}\left(\mathrm{sp}^{3}\right)$-centered radicals, accessed through oxidative (from $\mathrm{CF}_{3} \mathrm{SO}_{2} \mathrm{Na}$ ) and reductive (from $\mathrm{BrCF}_{2} \mathrm{CO}_{2} \mathrm{Et}$ ) photoredox transformations capable of substituting two $\mathrm{C}_{\mathrm{Het}}-\mathrm{H}$ bonds at the same time. This novel approach is strikingly different from that of ordinary semiconductors, which generally activate a single reactant either by oxidizing or reducing it, and the large band gaps of metal semiconductors commonly provoke recombination of either the non-reactive hole $(+)$ or spare electron $(-)$.

As for the photocatalyzed trifluoromethylation reactions of carbon-carbon multiple bonds, Ir-, and Ru- photocatalysts have amply been employed in trifluoromethylation reactions using Togni reagent, Umemoto reagent, triflic chloride, Langlois reagent, and $\mathrm{CF}_{3}-\mathrm{I}$ as sources of $\mathrm{CF}_{3}$ radicals, allowing the simultaneous incorporation of $\mathrm{CF}_{3}$ and other groups such as $\mathrm{NR}_{2}, \mathrm{OR}, \mathrm{Cl}, \mathrm{Br}, \mathrm{I}$, etc. Organic dyes, and small organic sensitizers have also been used as photocatalysts activated by visible light in trifluoromethylation reactions of multiple bonds. However, for these families of substrates, no all-organic visible-light-activated semiconductors have been employed. This area (i.e.: all-organic semiconductors for photocatalyzed trifluoromethylations of multiple bonds) is very promising and is expected to produce significant results in the near future, as can easily replace the use of transition-metal photocatalysts needed to accomplish many 
WILEY-VCH

trifluoromethylation strategies reviewed in the literature. This latter is particularly relevant in the pharmaceutical industry, where the avoidance of transition metals in synthetic protocols is pursued.

\section{Acknowledgements}

SVB and AP are research members of Consejo Nacional de Investigaciones Científicas y Técnicas (Conicet). The authors also wish to thank the following financial agencies: ANPCyT-PICT 2875/17, CONICET PIP 17, and UBACyT, Universidad de Buenos Aires.

Keywords: trifluoromethylation $\cdot$ photocatalytic trifluoromethylation $\cdot$ visible light photocatalysis • trifluoromethylation of carbon-carbon multiple bonds trifluoromethylation of heteroaromatics

[1] H. Mei, J. Han, S. Fustero, M. Medio-Simon, D. M. Sedgwick, C. Santi, R. Ruzziconi, and V. A. Soloshonok, Chem. A Eur. J. 2019, 25, 1179711819.

[2] (a) F. Borsini, K. Evans, K. Jason, F. Rohde, B. Alexander, S. Pollentier, CNS Drug Rev. 8 (2): 117-142. (b) T. O'Hare, W. C. Shakespeare, X. Zhu, C.A. Eide, V. M. Rivera, F. Wang, L. T. Adrian, T. Zhou, W. S. Huang, Q. Xu, C. A. Metcalf, J. W. Tyner, M. M. Loriaux, A. S . Corbin, S. Wardwell, Y. Ning, J.A. Keats, Y. Wang, R. Sundaramoorthi, M. Thomas, D. Zhou, J. Snodgrass, L. Commodore, T. K. Sawyer D. C. Dalgarno, M. W. Deininger, B. J. Druker, T. Clackson, Cancer Cell. 16 (5): 401-12.

[3] K. Ordan, F. Jahn, M. Aapro. (2015). Ann. Oncol. 2015, 26, 1081-90.

[4] (a) A. B Hounkpatin, A. Kreidenweiss, J. Held, Infection and Drug Resistance. 2019, 12, 553-570. (b) M. Kulke, D. MHörsch, M. Caplin, L. Anthony, E. Bergsland, K. Oberg, S. Welin, R. Warner, C. L. Bohas, P.L. Kunz, E. Grande, J. W. Valle, P. Lapuerta, P. Banks, S. Jackson, W. Jiang, T. Biran, M. Pavel, Ann. Oncol. 27 (6): 136-148.

[5] S. Pan, X. Wu, J. Jiang, W. Gao, Y. Wan, D. Cheng, D. Han, J. Liu, N. P. Englund, Y. Wang, S. Peukert, K. Miller-Moslin, J. Yuan, R. Guo, M. Matsumoto, A. Vattay, Y. Jiang, J. Tsao, F. Sun, A. C. Pferdekamper, S. Dodd, T. Tuntland, W. Maniara, J. F. Kelleher, Y. Yao, M. Warmuth, J. Williams, M. Dorsch, ACS Medicinal Chemistry Letters. 1 (3), 130-134.

[6] A. Rizzi, B. Campi, V. Camarda, S. Molinari, S. Cantoreggi, D. Regoli, C. Pietra, G. Calo, Peptides, 2012, 37, 86-97.

[7] D. J. Crona, M. D. Keisler, C. M. Walko, Ann Pharmacother. 2013, 47, 16851696.

[8] R. Alonso, A. Cuevas, and P. Mata, Core Evid. 2019, 14, 19-30.

[9] K.J. Wilby, N.A. Eissa, Eur. J. Drug Metab. Pharmacokinet. 2018, 43, 637 644.

[10] D. W. Grosenbach, K. Honeychurch, E. A.Rose, J. Chinsangaram, A. Frimm, B. Maiti, C. Lovejoy, I. Meara, P. Long, D. E. Hruby, N. Engl. J Med. 2018, 379, 44-53.

[11] For recent reviews on trifluoromethylation, see: a) H. Liu, Z. Gu, X. Jiang, Adv. Synth. Catal. 2013, 355, 617-626; (b) Y. Ye, M. S. Sanford, Synlett 2012, 23, 2005 - 2013; c) O. A. Tomashenko, V. V. Grushin, Chem. Rev. 2011, 111, 4475 - 4521; d) T. Furuya, A. S. Kamlet, T. Ritter, Nature 2011, 473, 470 - 477; e) T. Liu, Q. Shen, Eur. J. Org. Chem. 2012, 6679 - 6687; f) A. Studer, Angew. Chem. Int. Ed. 2012, 51, 8950 - 8958; Angew. Chem. 2012, 124, 9082 - 9090.

[12] Leading Reviews: a) C. K. Prier, D. A. Rankic, D. W. C. MacMillan, Chem. Rev. 2013, 113, 5322 - 5363; b) J. M. R. Narayanam, C. R. J. Stephenson, Chem. Soc. Rev. 2011, 40, $102-113$.

[13] C. Zhang, Adv. Synth. Catal. 2017, 359(3), 372-383.

[14] a) M. Rueping, S. Zhu, R. M. Koenigs, Chem. Commun. 2011, 47, 8679; b) Y. Q. Zou, L. Q. Lu, L. Fu, N. J. Chang, J. Rong, J. R. Chen, W. J. Xiao, Angew. Chem., Int. Ed. 2011, 50, 7171; c) D. P. Hari, T. Hering, B. König,
Org. Lett. 2012, 14, 5334; d) D. Hamilton, D. A. Nicewicz, J. Am. Chem. Soc. 2012, 134, 18577; e) D. P. Hari, P. Schroll. B. König, J. Am. Chem. Soc. 2012, 134, 2958; f) J. Grandjean, D. Nicewicz, Angew. Chem., Int. Ed. 2013, 52, 3967; g) S. Zhu, M. Rueping, Chem. Commun. 2012, 48, 11960; h) M. Rueping, C. Vila, Org. Lett. 2013, 15, 2092; i) D. J. Wilger, N. J. Gesmundo, D. A. Nicewicz, Chem. Sci. 2013, 4, 3160; j) A. U. Meyer, S. Jager, D. P. Hari, B. König, Adv. Synth. Catal. 2015, 357, 2050; k) W. Yoo, T. Tsukamoto, S. Kobayashi, Angew. Chem., Int. Ed. 2015, 54, 6587 ; I) H. Yin, P. J. Carroll, B. C. Manor, J. M. Anna, E. J. Schelter, J. Am. Chem. Soc. 2016, 138, 5984.

[15] (a) J. D. Nguyen, J. W. Tucker, M. D. Konieczynska, C. R. J. Stephenson, J. Am. Chem. Soc. 2011, 133, 4160; b) R. Tomita, Y. Yasu, T. Koike, M. Akita, Angew. Chem., Int. Ed. 2014, 53, 7144; c) A. Carboni, G. Dagousset, E. Magnier, G. Masson, Org. Lett. 2014, 16, 1240; d) X.-L. Yu, J.-R. Chen, D.-Z. Chen, W.-J. Xiao, Chem. Commun. 2016, 52, 8275.

[16] S. Barata-Vallejo, B. Lantaño, and A. Postigo, Chem. A Eur. J. 2014, 20, 16806-16829.

[17] (a) X. Liu, F. Xiong, X. Huang, L. Xu, P. Li, X. Wu, Angew. Chem., Int. Ed. 2013, 52, 6962; b) H. Egami, R. Shimizu, Y. Usui, M. Sodeoka, Chem. Commun. 2013, 49, 7346; c) P. Xu, K. Hu, Z. Gu, Y. Cheng, C. Zhu, Chem. Commun. 2015, 51, 7222; d) H.-L. Huang, H. Yan, G.-L. Gao, C Yang, W. Xia, Asian J. Org. Chem. 2015, 4, 674; e) S. Woo, D. Kim, J. Fluorine Chem. 2015, 178, 214.

[18] Visible Light Photocatalysis in Organic Chemistry. Edited by Corey R.J. Stephenson, Tehshik P. Yoon, David W.C. MacMillan. 2018 Wiley-VCH Verlag GmbH \& Co. KGaA. ISBN 978-3-527-3360-2

[19] (a) M. De Abreu, P. Belmont, and E. Brachet, Eur. J. Org. Chem. 2019, DOI: 10.1002/ejoc.201901146N. (b) lqbal, J. Jung, S. Park, E. J. Cho, Angew. Chem., Int. Ed. 2014, 53, 539-542.

[20] N. J. W. Straathof, S. E. Cramer, V. Hessel, T. Nöel, Angew. Chem., Int. Ed. 2016, 55, 15549- 15553.

[21] T. Chatterjee, N. Iqbal, Y. You, E. J. Cho, Acc. Chem. Res. 2016, 49, 2284-2294.

[22] D. A. Nagib, D. W. C. MacMillan, Nature 2011, 480, 224-228.

[23] T. Koike, M. Akita, Photocatalytic introduction of fluorinated groups. From Science of Synthesis, Photocatalysis in Organic Synthesis 2019, 559574.

[24] I. Ghosh, J. Khamrai, A. Savateev, N. Shlapakov, M. Antonietti, B. König, Science 2019, 365, 360-366.

[25] E. A. Meucci, S. N. Nguyen, N. M. Camasso, E. Chong, A. Ariafard, A. J. Canty, and M. S. Sanford, J. Am. Chem. Soc. 2019, 141, 12872-12879.

[26] T. Besset, C. Schneider, and D. Cahard, Angew. Chemie Int. Ed. 2012, 51, 5048-5050.

[27] (a) W. Jud, S. Maljuric, C. O. Kappe, and D. Cantillo, Org. Lett. 2019, 21, 7970-7975. (b) Y. Deng, F. Lu, S. You, T. Xia, Y. Zheng, C. Lu, G. Yang, Z. Chen, M. Gao, A. Lei, Chinese Journal of Chemistry 2019, 37, 817820.

[28] N. Iqbal, S. Choi, E. Ko, E. J. Cho, Tetrahedron Letters 2012, 53, 20052008.

[29] N. J. W. Straathof, H. P. L. Gemoets, X. Wang, J. C. Schouten, V. Hessel, and T. Nöel. Chem.Sus.Chem. 2014, 7, 1612-1617

[30] a) D. A. Nagib, M. E. Scott, D.W. C. MacMillan, J. Am. Chem. Soc. 2009, 131, 10875 - 10877; b) P. V. Pham, D. A. Nagib, D.W. C. MacMillan, Angew. Chem. Int. Ed. 2011, 50, 6119-6122; c) Y. Ye, M. S. Sanford, J. Am. Chem. Soc. 2012, 134, 9034 - 9037; d) C.-J. Wallentin, J. D. Nguyen, P. Finkbeiner, C. R. J. Stephenson, J. Am. Chem. Soc. 2012, 134, 8875 - 8884. (e) S. Mizuta, S. Verhoog, K. M. Engle, T. Khotavivattana, M. O'Duill, K. Wheelhouse, G. Rassias, M. Medebielle, V. Gouverneur, J. Am. Chem. Soc. 2013, 135, 2505 - 2508.

[31] J. Xie, X. Yuan, A. Abdukader, C. Zhu and J. Ma, Org. Lett. 2014, 16, 1768.

[32] (a) X. Pan, H. Xia, and J. Wu, Org. Chem. Frontiers, 2016, 3, 1163-1185. (b) G.-b. Roh, N. Iqbal, and E. J. Cho, Chin. J. Chem. 2016, 34, 459464. (c) Z. Jia, Y. Yuan, X. Zong, B. Wu, J. Ma, Chinese Chemical Letters 2019, 30, 1488-1494.

[33] N. J. W. Straathof, D. J. G. P. van Osch, A. Schouten, X. Wang, J. C. Schouten, V. Hessel and T. Noël. J. Flow Chem. 2014, 4, 12-17.

[34] Q. Lefebvre, Synlett 2017, 28, 19-23.

[35] L. Li, X. Mu, W. Liu, Y. Wang, Z. Mi and C. Li, J. Am. Chem. Soc. 2016, $138,18,5809-5812$. 
[36] S. Corsico, M. Fagnoni, D. Ravelli, Photochemical \& Photobiological Sciences, 2017, 16, 1375-1380

[37] I. Abdiaj, C. Bottechia, J. Alcazar, T. Nöel, Synthesis 2017, 49, 4978-4985.

[38] B. Chang, H. Shao, P. Yan, W. Qiu, Z. Weng, and R. Yuan, ACS Sustainable Chem. Eng. 2017, 5, 334-341.

[39] L. Cui, Y. Matusaki, N. Tada, T. Miura, B. Uno and A. Itoh, Adv. Synth. Catal. 2013, 355, 2203.

[40] Q. Lefebvre, N. Hoffmann and M. Rueping, Chem. Comm. 2016, 52, 24932496.

[41] M. Baar and S. Blechert, Chem. Eur. J., 2015, 21, 526.

[42] (a) N. J. W. Straathof, S. E. Cramer, V. Hessel, T. Noël, Angew. Chem., Int. Ed. 2016, 55, 15549-15553. (b) L Zhu, L.-S. Wang, B. Li, B. Fu, C.-P. Zhang, W. Li, Chem. Comm. 2016, 52, 6371-6374. (c) Y. Cheng, S. Yu, Org. Lett. 2016, 18, 2962-2965.

[43] X. Chen, Z. Tan, Q. Gui, L. Hu, J. Liu, J. Wu, and G. Wang, Chem. Eur. J. 2016, 22, $6218-6222$.

[44] C. Tian, Q. Wang, X. Wang, G. An, and G. Li, J. Org. Chem. 2019, 84, 14241-14247.

[45] C. Tian, L.-M. Yang, H.-T. Tian, G.-H. An, G.-M. Li, J. Fluorine Chem. 2019, 219, 23-28.

[46] S. P. Pitre, C. D. McTiernan, H. Ismaili, J. C. Scaiano, ACS Catal. 2014, 4, 2530-2535

[47] (a) A. Murugan, V. N. Babu, A. Polu, N. Sabarinathan, M. Bakthadoss, and D. S. Sharada, J. Org. Chem. 2019, 84, 7796-7803 . (b) Q. Zhou, S. Xu, R. Zhang, Tetrahedron Lett. 2019, 60, 734-738.

[48] (a) R. L. Hartman, J. P. McMullen, K. F. Jensen. Angew. Chem. Int. Ed. 2011, 50, 7502-7519. (b) D. T. McQuade, P. H. Seeberger. J. Org. Chem 2013, 78, 6384-6389. (c) N. J. W. Straathof, Y. Su, V. Hessel, T. Nöel. Nature Protocols, 2016, 11, 10-21. (d) W. Li, K. Liu, R. Simms, J. Greener D. Jagadeesan, S. Pinto, A. Gunter, E. Kumacheva, J. Am. Chem. Soc. 2012, 134, 3127-3132. (e) C. Bottecchiaa, R. Martín, I. Abdiajc, E. Crovinia, J. Alcazarc, J. Ordunad, M. J. Blesad, J. R. Carrillo, P. Prietob and T. Noël, Advanced Synthesis \& Catalysis 2019, 361, 945-950. (f) D. Cambié, J. Dobbelaar. P. Riente, J. Vanderspikken, C. Shen, P. H. Seeberger, K. Gilmore, M. G. Debije, T. Nöel. Angew. Chemie Int. Ed. 2019, 58, 14374-14378. (g) D. Cambié, F. Zhao, V. Hessel, M. G. Debije, T. Nöel, Angew.Chem. Int. Ed. 2017, 56, 1050-1054.

[49] (a) F. Ye, F. Berger, H. Jia, J. Ford, A. Wortman, J. Börgel, C. Genicot, and T. Ritter. Angew. Chem. Int. Ed. 2019, 58, 14615-14619. (b) B. Maiti, A. Abramov, R. Pérez-Ruiz, D. Díaz Díaz, Acc. Chem. Res. 2019, 52, 1865-1876. (c) T. Zhang, X. Guo, Y. Shi, C. He, C. Duan, Nat. Commun. 2018, 9, DOI 10.1038/s41467-018-05919-6.

[50] S. Sarina, E. R. Waclawik, H. Zhu, Green Chem. 2013, 15, 1814-1833.

[51] W. Ye, R. Long, H. Huang, Y. Xiong, J. Mater. Chem. C 2017, 5, 1008-1021.

[52] Z. Bazyar and M. Hosseini-Sarvari, Org. Process Res. Dev. 2019, 23, 23452353.

[53] Y. Tong, H. Pan, W. Huang, W. Qiu, Z. Ding, C. Xu and R. Yuan, New J. Chem. 2019, 43, 8741.

[54] Q.-Y. Lin, X.-H. Xu, and F.-L. Qing, J. Org. Chem. 2014, 79, 10434-10446.

[55] E. H. Oha, H. J. Kim, S. B. Han, Synthesis 2018, 50, 3346-3358.

[56] M. Khalid, S. Mohammed. Recent trifluoromethylation reactions. A mini review. Oriental J. Chem. 2018, 34, 2708-2715.

[57] T. Koike, M. Akita, Accounts of Chemical Research 2016, 49, 1937-1945.

[58] M. Asano, R. Tomita, T. Koike, M. Akita, J. Fluorine Chemistry 2015, 179, 83-88.

[59] K. G. Ghosh, P. Chandu, S. Mondal, D. Sureshkumar, Tetrahedron 2019, 75, 4471-4478.

[60] J. Moon, Y. K. Moon, D. D. Park, S. Choi, Y. You, and E. J. Cho, J. Org. Chem. 2019, 84, 12925-12932.

[61] X. Yu, P. Dai, Y.-C. Zhu, W.-H. Zhang, and C. Deng, ChemCatChem 2018, 10, 5115-5118.

[62] For selected examples, see: (a) Y. Yasu, T. Koike, M. Akita, Angew. Chem., Int. Ed. 2012, 51, 9567-9571. (b) N. Noto, K. Miyazawa, T. Koike, M. Akita, Org. Lett. 2015, 17, 3710-3713. (c) R. Tomita, T. Koike, M. Akita, Angew. Chem., Int. Ed. 2015, 54, 12923-12927. R. Tomita, Angew. Chem. 2015, 127, 13115-13119. (d) Y. Ran, Q.-Y. Lin, X.-H. Xu, F.- L. Qing, J. Org. Chem. 2016, 81, 7001-7007. (e) N. Noto, T. Koike, M. Akita, Chem. Sci. 2017, 8, 6375- 6379. (f) M. Daniel, G. Dagousset, P. Diter,
P.-A. Klein, B. Tuccio, A.-M. Goncalves, G. Masson, E. Magnier, Angew. Chem., Int. Ed. 2017, 56, 3997-4001.

[63] X. Geng, F. Lin, X. Wang, N. Jiao, Org. Lett. 2017, 19, 4738-4741.

[64] For selected examples, see (a) X.-J.Tang, W. R. Dolbier, Jr. Angew. Chem., Int. Ed. 2015, 54, 4246- 4249. (b) C. Carboni, G. Dagousset, E. Magnier, G. Masson, Synthesis 2015, 47, 2439-2445. (c) J. Fang, Z.-K. Wang, S.W. Wu, W.-G. Shen, G.-Z. Ao, F. Liu, Chem. Commun. 2017, 53, 7638-7641.

[65] For selected examples, see: (a) P. Xu, J. Xie, Q. Xue, C. Pan, Y. Cheng, C. Zhu, Chem. - Eur. J. 2013, 19, 14039-14042. (b) X. J. Tang, C. Thomoson, W. R. Dolbier, Jr. Org. Lett. 2014, 16, 4594-4597. (c) A. Carboni, G. Dagousset, E. Magnier, G. Masson, Chem. Commun. 2014, 50, 14197-14200. (d) C. Liu, W. Zhao, Y. Huang, H. Wang, B. Zhang, Tetrahedron 2015, 71, 4344-4351. (e) L. Zheng, C. Yang, Z. Xu, F. Gao, W. Xia, J. Org. Chem. 2015, 80, 5730-5736. (f) S. B. Woo, D. Y. Kim, J. Fluorine Chem. 2015, 178, 214-218. (g) V. R. Yatham, Y. Shen, R. Martin, Angew. Chem., Int. Ed. 2017, 56, 10915- 10919.

[66] G. Dagousset, A. Carboni, E. Magnier, and G. Masson, Org. Lett. 2014, 16 4340-4343

[67] G. Levitre, G. Dagousset, E. Anselmi, B. Tuccio, E. Magnier, and G. Masson, Org. Lett. 2019, 2, 6005-6010.

[68] S. W. Oh, Y. R. Malpani, N. Ha, Y.-S. Jung, S. B. Han, Org. Lett. 2014, 16, $1310-1313$.

[69] D. B. Bagal, G. Kachkovskyi, M. Knorn, T. Rawner, B. M. Bhanage, and O Reiser, Angew. Chemie Int. Ed. 2015, 54, 6999-7002.

[70] (a) M. Pirtsch, S. Paria, T. Matsuno, H. Isobe, O. Reiser, Chem. Eur. J. 2012, 18, 7336 - 7340; b) S. Paria, M. Pirtsch, V. Kais, O. Reiser, Synthesis 2013, 45, 2689 - 2698. For a review on copper in photocatalysis see S. Paria, O. Reiser, ChemCatChem 2014, 6, 2477 2483.

[71] P. J. Hogan, B. G. Cox, Org. Process Res. Dev. 2009, 13, $875-879$

[72] J. R. DeBergh, N. Niljianskul, S. L. Buchwald, J. Am. Chem. Soc. 2013, 135, $10638-10641$.

[73] X. Zhou, G. Li, Z. Shao, K. Fang, H. Gao, Y. Lib and Y. She, Org. Biomol. Chem. 2019, 17, 24.

[74] Y.-T. He, D. Kang, I. Kima, and S. Hong, Green Chem. 2018, 20, 5209.

[75] (a) D. Cantillo, O. de Frutos, J.A. Rincón, C. Mateos, C. O. Kappe, Org. Lett. 2014, 16, 896. (b) J. Jacquet, S. Blanchard, E. Derat, M. Desage-El Murr, L. Fensterbank, Chem. Sci. 2016, 7, 2030. (c) L. Li, Q.-Y. Chen, Y. Guo, J. Org. Chem. 2014, 79, 5145. (d) J.-A. Ma, D. Cahard, J. Org. Chem. 2003, 68, 8726.

[76] (a) X. Su, H. Huang, Y. Yuan, Y. Li, Angew. Chem., Int. Ed. 2017, 56, 1338. (b) T. Kawamoto, R. Sasaki, A. Kamimura, Angew. Chem., Int. Ed. 2017 $56,1342$.

[77] H.-T. Qin, S.-W. Wu, J.-L. Liua and F. Liu, Chem. Commun. 2017, 53, 16961699.

[78] (a) S. Park, J. M. Joo, and E. J. Cho, Eur. J. Org. Chem. 2015, 4093-4097. (b) Y. R. Malpani, B. K. Biswas, H. S. Han, Y.-S. Jung, and S. B. Han, Org. Lett. 2018, 20, 1693-1697.

[79] E. Kim, S. Choi, H. Kim, E. J. Cho, Chem. - Eur. J. 2013, 19, 6209.

[80] P. Xu, J. Xie, Q.-C. Xue, C.-D. Pan, Y.-X. Cheng, C.-J. Zhu. Chem. - Eur. J. 2013, 19, 14039.

[81] Y. Yasu, Y. Arai, R. Tomita, T. Koike, M. Akita, Org. Lett. 2014, 16, 780.

[82] Q.-H. Deng, J.-R. Chen, Q. Wei, Q.-Q. Zhao, L.-Q. Lu, W.-J. Xiao, Chem. Commun. 2015, 51, 3537.

[83] B. Sahoo, J.-L. Li, F. Glorius, Angew. Chem., Int. Ed. 2015, 54, 1157711580.

[84] Q. Wei, J.-R. Chen, X.-Q. Hu, X.-C. Yang, B. Lu, and W.-J. Xiao, Org. Lett. 2015, 17, 4464-4467.

[85] F. Gao, C. Yang, G.-L. Gao, L. Zheng, and W. Xia, Org. Lett. 2015, 17, 3478-3481.

[86] G. Zou and X. Wang, Org. Biomol. Chem. 2017, 15, 8748.

[87] X. Yuan, M.-W. Zheng, Z.-C. Di, Y.-S. Cui, K.-Q. Zhuang, L.-Z. Qin, Z. Fang, J.-K. Qiu, G. Lib, and K. Guo, Adv. Synthesis \& Cat. 2019, 361, 18351845 .

[88] (a) M.-j. Bua, G.-p. Lua, C. Cai, Cat. Comm. 2018, 114, C, 70-74. (b) X Yuan, M. W. Zheng, Z. C. Di, Y. S. Cui, K. Q. Zhuang, L. Z. Qin, Z. Fang, J. K. Qiu, G. Li, K. Guo, Adv. Synth. Catal. 2019, 361, 1835-1845. 


\section{WILEY-VCH}

\section{REVIEW}

[89] S. Cai, Y. Tian, J. Zhang, Z. Liu, M. Lu, W. Weng, M. Huang, Adv. Synth. \& Cat. 2018, 360, 4084-4088.

[90] P. Chandu, K. G. Ghosh, D. Das, D. Sureshkumar, Tetrahedron 2019, 75, 130641.

[91] P. Chandu, K. G. Ghosh, D. Das, D. Sureshkumar, J. Org. Chem. 2019, 84, 13, 8771-8781.

[92] A. K. Yadav, A. K. Sharma, K. N. Singh, Org. Chem. Front. 2019, 6, 989993. 
WILEY-VCH

\section{Entry for the Table of Contents}

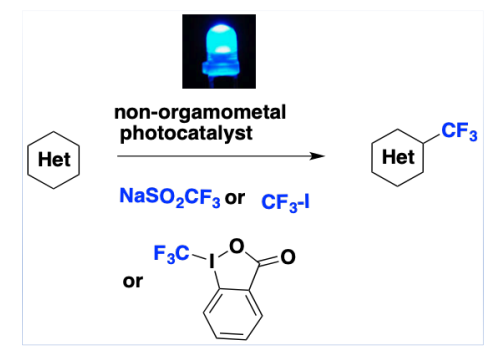

New visible-light-photocatalytic trifluoromethylation strategies for (hetero)aromatic compounds and carbon-carbon multiple bonds involve non-organometal photocatalysts such as all-organic semiconductors and small-molecule sensitizers compatible with the requirements of the pharmaceutical industry 